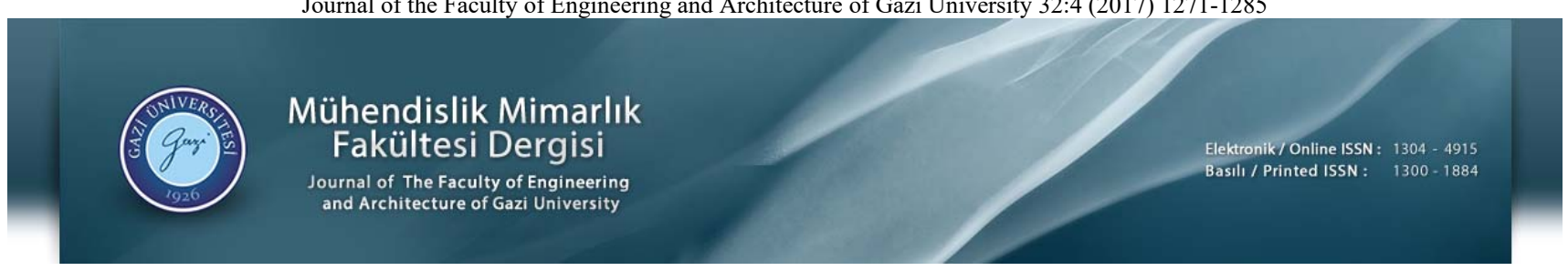

\title{
HPA algoritması ile çok makinalı güç sistemi kararlı kılıcısı tasarımı
}

\author{
Serdar Ekinci ${ }^{1 *(1)}$, Baran Hekimoğlu \\ ${ }^{1}$ Batman Üniversitesi, Mühendislik Mimarlık Fakültesi, Bilgisayar Mühendisliği Bölümü, 72060, Batman, Türkiye \\ ${ }^{2}$ Batman Üniversitesi, Mühendislik Mimarlık Fakültesi, Elektrik-Elektronik Mühendisliği Bölümü, 72060, Batman, Türkiye
}

Ö N E Ç I K A N L A R

- HPA, yeni bir hibrit optimizasyon algoritmasıdır.

- HPA, güç sisteminin dinamik kararlılığını oldukça iyileştirmektedir.

- Yeni hibrit algoritmanın PSO ve ABC'ye göre üstünlüğü

Makale Bilgileri

Geliş: 15.08 .2016

Kabul: 19.06.2017

DOI:

10.17341/gazimmfd.369716

Anahtar Kelimeler:

Güç sistemi kararlı kılıcısı, çok makinalı güç sistemi, yapay arı kolonisi algoritmas1,

parçacık sürüsü optimizasyonu, hibridizasyon

\section{ÖZET}

Bu makale, parçacık sürüsü optimizasyonu (PSO) ve yapay arı kolonisine (ABC) dayalı, çok makinalı güç sisteminde güç sistemi kararlı kılıcısının (PSS) optimal tasarımı için iyimser sonuçlar bulmak için güçlü yetilere sahip HPA tekniği adında yeni bir hibrit yaklaşımı tanımlamaktadır. PSS parametrelerinin en uygun ayarlarının elde edilmesi için PSS parametrelerini seçme problemi, özdeğer tabanlı bir amaç fonksiyonu ile basit bir optimizasyon problemine çevrildi ve HPA tekniği kullanılarak çözüldü. Önerilen HPA tabanlı PSS tasarımının etkinliği özdeğer analizi, zaman domeni simülasyonları ve bazı performans indeksleri aracılığıyla farklı arızalar altındaki 3-makinalı 9-baralı güç sistemi üzerinde doğrulandı. Bu çalışmaların sonuçları, HPA algoritmasının PSS parametrelerinin ayarlanması için alternatif ve daha etkin bir iyileştirici olduğunu ve PSO ile ABC'ye oranla güç sisteminin dinamik kararlılığını büyük oranda artırdığını göstermiştir. Ayrıca hesaplama zamanı, yaklaşım hızı ve çözüm kalitesi açısından HPA algoritmasının PSO ve $A B C$ 'ye göre potansiyeli ve üstünlügü kanıtlanmıştır.

\section{Multi-machine power system stabilizer design via HPA algorithm}

\section{H I G H L I G H T S}

- HPA is a new hybrid optimization algorithm.

- HPA greatly enhances the dynamic stability of the power system.

- The superiority of new hybrid algorithm over PSO and ABC

Article Info

Received: 15.08.2016

Accepted: 19.06.2017

DOI:

10.17341/gazimmfd.369716

Keywords:

Power system stabilizer, multi-machine power

system,

artificial bee colony

algorithm,

particle swarm optimization,

hybridization

\begin{abstract}
This paper describes a novel hybrid approach based on particle swarm optimization (PSO) and artificial bee colony algorithm (ABC) called HPA technique that has powerful capabilities to discover the optimistic results for optimal design of power system stabilizer (PSS) in a multi-machine power system. For achieving optimal tuning of PSS parameters, the problem of selecting PSS parameters is converted to a simple optimization problem with an eigenvalue-based objective function and is solved by using the HPA technique. The effectiveness of the proposed HPA based-PSS design is verified through eigenvalue analysis, time domain simulations and some performance indices on a 3-machine 9-bus power system under different disturbances. The results of these studies show that the HPA algorithm is an alternative and more effective optimizer for tuning of PSS parameters and enhance greatly the dynamic stability of the power system compared with PSO and ABC. Also, the potential and superiority of the HPA algorithm over PSO and ABC in terms of computational time, convergence rate and solution quality is proved.
\end{abstract}




\section{GIIRIŞ (INTRODUCTION)}

Elektrik güç sistemi, karmaşık ve lineer olmayan bir sistem olduğu için matematiksel modelinin çıkarılması oldukça zordur. Güç sistemleri mekanik doğası gereği, sistemde düşük frekanslı salınımlar üretir ve bu istenmeyen salınımlar, kararlılık ile sistemin performansını önemli ölçüde etkileyecek ve iletim hattının kapasitesini de sınırlayacaktır [1, 2]. Bu problemle baş edebilmek amacıyla, jeneratörlerin uyarma sisteminde destekleyici bir kontrolör kullanılır [3, 4]. PSS olarak bilenen bu destekleyici kontrolör; esnek, kolay uygulanabilir ve düşük maliyetli olmasından ötürü, küçük işaret salınımlarını söndürmek ve sistemin dinamik kararlılığını düzeltmek için güç sistemlerinde geniş ölçüde kullanılır [5, 6]. Adaptif kontrol, optimal kontrol, akıllı kontrol ve değişken yapılı kontrol gibi bir takım teknikler PSS tasarımında kullanılmıştır [7, 8]. Kontrol yasası, doğrusallaştırılmış makine modeli şartına dayalı olduğu ve aynı zamanda kontrol parametreleri belirli nominal çalışma ayarlarında düzenlendiği için bu mevcut tekniklerin birçoğunun dezavantajı bulunmaktadır [6]. Ayrıca, sistem koşulları büyük arıza durumlarında lineer olamayan şekilde değişeceğinden dolayı kontrolörlerin parametreleri her durum için etkili değildir [6].

Geleneksel optimizasyon tekniklerinin lineer olmayan güç sistemleri problemlerini çözmedeki yetersizliğinden dolayı; son y1llarda genetik algoritma (genetic algorithm, GA) [9, 10], tabu arama algoritması (tabu search algorithm) [1], diferansiyel evrim (differential evolution) $[11,12]$, parçacık sürüsü optimizasyonu (particle swarm optimization, PSO) $[13,14]$, yarasa algoritmas1 (bat algorithm) $[15,16]$, yapay ar1 kolonisi (artificial bee colony, ABC) $[17,18]$ ve benzeri diğer sezgisel arama algoritmaları [19, 20], PSS tasarım problemlerine başarıyla uygulanmıştır. Bu algoritmalardan PSO ve $A B C$ sürü zekasının yeni üyeleridir ve bu algoritmaların basit yapısı ve kompleks optimizasyon problemlerini hızlı çözebilme yetenekleri vardır [3]. Balık ve kuş sürülerinden esinlenerek geliştirilmiş $\mathrm{PSO}$, tek makinalı sonsuz baralı ve çok makinalı güç sistemlerinde PSS parametrelerinin optimal ayarlanmasında kullanılmıştır [21]. PSO algoritması iyi bir yararlanma yetisine sahiptir ancak popülasyon ya da parçacıklar yerel bir minimuma sıkıştığında, PSO'nun yerel minimumdan kurtulmasını sağlayacak becerisi bulunmamaktadır [22]. Bal arısı kolonilerinin besin bulma davranışlarından esinlenerek geliştirilmiş $\mathrm{ABC}$ algoritması ise yeni bir optimizasyon tekniği olmasına rağmen, diğer algoritmalara göre PSS tasarımda oldukça etkili olduğu kanıtlanmıştır [17, 18]. Her ne kadar ABC algoritması etkili araştırma yetisine sahip olsa da, yararlanma becerisi oldukça zayıftır [22].

Literatürde $\mathrm{PSO}$ ve $\mathrm{ABC}$ ile ilgili yapılmış çalışmalar üzerindeki analiz, ABC algoritmasının güçlü global arama yetisine sahip olduğunu ancak zayıf yerel arama yetisinin olduğunu gösterirken [22]; PSO algoritmasının güçlü yerel arama yetisine sahip olduğunu ancak zayıf global arama yetisinin olduğunu göstermektedir [22]. Güçlü global arama yetisini sağlamak amacıyla, popülasyondaki çeşitlilik de iterasyon sırasında korunmuştur ancak güçlü yerel arama yetisini de sağlayabilmesi için popülasyon iterasyon sırasında doymaya (yararlanma) ulaşmalıdır [22]. Böylece algoritmalardaki keşif (çeşitlendirme) ve yararlanma (yoğunlaştırma), optimizasyon problemleri için daha kaliteli sonuçların elde edilmesi için dengelenmelidir [22]. Bu nedenle yeni bir evrimsel hesaplama tekniği olan hibrit algoritma kısacası HPA, Kıran tarafindan önerildi ve sunuldu [22]. PSO ve ABC algoritmalarının hibrit bileşimi olan HPA algoritmasının yerel ve global arama yetileri, parçacık sürüsü ve arı kolonisi arasında bilgi akışını sağlayarak daha kaliteli sonuçlar elde etmek için dengelenmiştir [22]. Böylelikle, HPA diğer sezgisel tekniklerin aksine global ve yerel keşif yetilerini iyileştirerek, esnek ve iyi dengelenmiş bir mekanizmaya sahip olur [22]. Yapılan literatür çalışmaları sonucunda, sezgisel algoritmalar içerisinde yeni ve efektif bir optimizasyon teknik olan HPA algoritması ile PSS parametrelerinin ayarının yapılmadığı görülmüştür. $\mathrm{Bu}$ çalışmada, HPA algoritması güç sistemlerinde kararlı kılıcı olarak görev yapan PSS cihazının parametrelerinin en uygun değerlerinin bulunması amacıyla ilk kez uygulanmıştır. PSS tasarım problemi, özdeğer tabanlı bir amaç fonksiyonu ile bir optimizasyon problemi olarak formüle edildi ve daha sonra bu optimizasyon problemini çözmek amaciyla HPA algoritmasından yararlanıldı. Önerilen hibrit yaklaşımın etkinliği ve sağlamlığını incelemek için çok makinalı örnek bir güç sistemi ele alındı. Önerilen kararlı kılıcının performansı ve geçerliliğini belirlemek amacıyla, sistemdeki bozucu etkiler de göz önüne alınarak; özdeğer analizi, lineer olmayan zaman domeni simülasyon sonuçları gerçekleştirildi. Ayrıca, tasarlanan hibrit tabanlı PSS (HPAPSS) ile PSO algoritması tabanlı PSS (PSOPSS) ve ABC algoritması tabanlı PSS (ABCPSS) karşılaştırılmalı olarak incelendi.

\section{GÜÇ SİSTEMİ MODELİ (POWER SYSTEM MODEL)}

Yüksek dereceden lineer olmayan özelliğe sahip bir elektrik güç sisteminin matematiksel modeli bir takım diferansiyel ve cebirsel denklemlerle ifade edilebilir. Bu çalışmada, çok makinalı güç sistemlerinde küçük işaret kararlılığ 1 ve geçici hal kararlılık çalışmaları için statik uyarmalı akı sönümlü makine modeli ele alındı [21]. Uyarma sistemi ve PSS ilave edilmiş $n$-makinalı $m$-baralı bir senkron makinanın dinamiği Eş. 1- Eş. 7'de ifade edilmiştir [23].

$$
\begin{aligned}
& \dot{\delta}_{i}=\omega_{S}\left(\omega_{i}-1\right)=\omega_{s} \Delta \omega_{i} \\
& \dot{\omega}_{i}=\frac{P_{m i}}{M_{i}}-\frac{P_{e i}}{M_{i}}-\frac{D_{i}\left(\omega_{i}-1\right)}{M_{i}} \\
& \dot{E}_{q i}^{\prime}=-\frac{E_{q i}^{\prime}}{T_{d o i}^{\prime}}-\frac{\left(x_{d i}-x_{d i}^{\prime}\right) i_{d i}}{T_{d o i}^{\prime}}+\frac{E_{f d i}}{T_{d o i}^{\prime}}
\end{aligned}
$$




$$
\dot{E}_{f d i}=-\frac{E_{f d}}{T_{A i}}+\frac{K_{A i}}{T_{A i}}\left(V_{r e f i}+V_{S i}-V_{i}\right)
$$

$$
V_{i} \sin \left(\delta_{i}-\theta_{i}\right)+r_{s i} i_{d i}-x_{q i} i_{q i}=0
$$

$$
E_{q i}^{\prime}-V_{i} \cos \left(\delta_{i}-\theta_{i}\right)-r_{s i} i_{q i}-x_{d i}^{\prime} i_{d i}=0
$$

$$
\left[\begin{array}{c}
\bar{I}_{1} \\
\vdots \\
\bar{I}_{n}
\end{array}\right]=\left[\overline{\mathbf{Y}}_{\text {red }}\right]\left[\begin{array}{c}
\bar{V}_{1} \\
\vdots \\
\bar{V}_{n}
\end{array}\right]
$$

$\mathrm{i}=1,2, \ldots, \mathrm{n}$ olmak üzere Eş. 1-Eş. 4 makine ve uyarmalara ilişkin diferansiyel denklemleri; Eş. 5ve Eş. 6 kutupsal formdaki stator cebirsel denklemleri ve Eş. 7 ise akım-denge formundaki şebeke denklemini göstermektedir. Yukarıdaki eşitliklerde $\omega_{\mathrm{s}}=2 \pi \mathrm{f}$ ve $\mathrm{M}=2 \mathrm{H}$ olmak üzere; $i$. makine için $\delta_{\mathrm{i}}$ rotor açısını, $\omega_{\mathrm{i}}$ rotor hızını, $\omega_{\mathrm{s}}$ senkron hızı, $\mathrm{H}_{\mathrm{i}}$ eylemsizlik sabitini, $\mathrm{P}_{\mathrm{mi}}$ generatör giriş gücünü, $\mathrm{P}_{\mathrm{ei}}$ elektriksel çıkış gücünü, $\mathrm{x}_{\mathrm{di}} d$-ekseni senkron reaktansını, $\mathrm{x}^{\prime}{ }_{\mathrm{di}} d$-ekseni geçici reaktansın1, $\mathrm{x}_{\mathrm{qi}} q$-ekseni senkron reaktansını, $\mathrm{E}_{\mathrm{qi}}^{\prime}, \mathrm{x}_{\mathrm{di}}^{\prime}$ gerisindeki iç gerilimini, $\mathrm{D}_{\mathrm{i}}$ sönüm katsayısını, $\mathrm{i}_{\mathrm{di}} d$-ekseni armatür akımını, $\mathrm{i}_{\mathrm{qi}} q$-ekseni armatür akımını, $\mathrm{T}_{\text {doi }}^{\prime}$ açık devre $d$-ekseni zaman sabitini, $\mathrm{E}_{\text {fdi }}$ uyarma sistemi gerilimini, $\mathrm{V}_{\text {refi }}$ referans gerilimini, $\mathrm{K}_{\mathrm{Ai}}$ otomatik gerilim regülatörü kazanç sabitini, $\mathrm{T}_{\mathrm{Ai}}$ otomatik gerilim regülatörü zaman sabitini, $\mathrm{V}_{\mathrm{i}}$ uç gerilimini, $I_{i}$ kompleks enjekte edilen generatör akımını ve $Y_{\text {red }}$ ise sistemin indirgenmiş matrisini göstermektedir [21]. PSS tasarımında genellikle bir denge noktası civarında doğrusallaştırılmış artırımlı modeller kullanılır [7]. Bu nedenle uyarma sistemi ve PSS ilave edilmiş bir güç sisteminin lineer modeli Eş. 8'de görüleceği biçimde olacaktır $[7,21]$.

$$
\Delta \dot{\mathrm{x}}=\mathrm{A}_{\mathrm{sys}} \Delta \mathrm{x}+\mathrm{B} \Delta \mathrm{u}
$$

Eş. 8'de $\mathrm{A}_{\text {sys }}$ durum değişkenleri matrisi (sistem matrisi), B giriş matrisi, $\Delta \mathrm{x}$ durum değişkenleri vektörü ve $\Delta \mathrm{u}$ giriş değişkenleri vektörüdür. Bu çalışmada $\Delta \mathrm{x}_{\mathrm{i}}=\left[\Delta \delta_{\mathrm{i}} \Delta \omega_{\mathrm{i}} \Delta \mathrm{E}_{\mathrm{qi}}^{\prime}\right.$ $\left.\Delta \mathrm{E}_{\mathrm{fdi}}\right]^{\mathrm{T}}$ ve $\Delta \mathrm{u}$ ise PSS çıkış işaretleridir. Buradaki PSS tasarımının amacı, $\mathrm{A}_{\mathrm{sys}}$ sistem matrisinin özdeğerleri olan $\lambda_{\mathrm{i}}=\sigma_{\mathrm{i}} \pm \mathrm{j} \omega_{\mathrm{i}}$ değerlerini karmaşı düzlemin sol tarafina yerleştirmektir [21]. Bu özdeğerler reel ya da kompleks olabilir. $\sigma_{\mathrm{i}}$ ve $\omega_{\mathrm{i}}, i$. özdeğerin reel ve imajiner kısımları olmak üzere $i$. özdeğerin sönüm oran $\zeta_{\mathrm{i}}=-\frac{\sigma_{\mathrm{i}}}{\sqrt{\sigma_{\mathrm{i}}^{2}+\omega_{\mathrm{i}}^{2}}}$ olarak tanımlanır.

\section{PSO, ABC VE HPA ALGORITMALARINA GENEL BAKIŞ (OVERVIEW OF PSO, ABC AND HPA ALGORITHMS)}

\subsection{Parçacık Sürüsü Optimizasyonu (Particle Swarm Optimization)}

Eberhart ve Kennedy tarafından 1995 yılında kuş ve balık sürülerinin besin bulma davranışlarından esinlenerek bulunan ve geliştirilen parçacık sürüsü optimizasyonu, sürü zekasına dayalı stokastik bir optimizasyon tekniğidir [24]. $\mathrm{Bu}$ nedenle PSO tek bireyin yerine, olası çözümlerden oluşan bir popülasyon ile çalışmaktadır [25]. PSO tekniğindeki sürünün her bir parçacığı, bazı problemlerin veya fonksiyonların arama uzayına yerleştirilir ve her bir parçacığın kendi mevcut konumlarındaki uyumluluk fonksiyonunun değeri hesaplanır. Ondan sonra her bir parçacık, arama uzayında kendisinin mevcut ve rastgele dağılan sürünün bir veya daha fazlasının elde ettiği en iyi yerlerin geçmiş bazı yönlerini birleştirerek hareketini belirler. Tüm parçacıklar yer değiştirdikten sonra bir sonraki iterasyon gerçekleşir. Sonuçta, toplu olarak yiyecek arayan kuş ve balık sürüleri gibi sürü bir bütün olarak uyumluluk fonksiyonunun en iyisine yaklaşarak hareket eder [26].

PSO tekniğinde arama uzayındaki her bireyin yörüngesi, kendi uçuş deneyimi ve arama uzayındaki diğer parçacıkların uçuş deneyimlerine göre her parçacığın hızı dinamik olarak değiştirilerek ayarlanır. $D$-boyutlu arama uzayındaki $i$. parçacığın konum ve hız vektörleri sırasıyla $\mathrm{X}_{\mathrm{i}}=\left(\mathrm{x}_{\mathrm{i} 1} ; \mathrm{x}_{\mathrm{i} 2} ; \ldots ; \mathrm{x}_{\mathrm{iD}}\right)$ ve $\mathrm{V}_{\mathrm{i}}=\left(\mathrm{v}_{\mathrm{i} 1} ; \mathrm{v}_{\mathrm{i} 2} ; \ldots ; \mathrm{v}_{\mathrm{iD}}\right)$ olarak gösterilebilir. Kullanıcı tanımlı amaç fonksiyonuna göre, her birey kendi en iyi değerini pbest ve her parçacık grubu kendi en iyi değerini gbest olarak tanımlamakta ve bilgilerini hafızalarında tutmaktadır [13]. Her bir parçacık konumunu ve hızını, kendi en iyi konumuna (pbest) ve tüm sürünün en iyi konumuna (gbest) göre günceller [13]. Her bir iterasyonda pbest ve gbest değerleri bulunduktan sonra parçacıkların yeni hız ve konumları Eş. 9 ve Eş. 10 kullanılarak hesaplanır [26].

$$
\begin{aligned}
& v_{i d}^{k+1}=w \times v_{i d}^{k}+c_{1} \times r_{1} \times \\
& \left(\text { pbest }_{i d}-x_{i d}^{k}\right)+c_{2} \times r_{2} \times\left(\text { gbest }_{d}-x_{i d}^{k}\right) \\
& x_{i d}^{k+1}=x_{i d}^{k}+v_{i d}^{k+1}
\end{aligned}
$$

Burada, $\mathrm{i}=1,2, \ldots, \mathrm{NP}$ ve NP sürü büyüklüğü; $w$ her bir iterasyon için lineer olarak azalan atalet ağırlı $\breve{g}_{1} ; c_{1}$ ve $c_{2}, 0,2-$ 2 aralığında olup kavramsal ve sosyal hizlandırma sabitleridir. $r_{1}$ ve $r_{2}$ ise $[0-1]$ aralığında olan rastgele sayılardır [26].

\subsection{Yapay Arı Kolonisi Algoritması \\ (Artificial Bee Colony Algorithm)}

Yapay arı kolonisi algoritması, Karaboğa tarafindan bal arıs1 kolonilerinin besin bulma davranışlarından esinlenerek geliştirilmiş sürü zekasına dayalı bir optimizasyon tekniğidir $[27,28]$. Genetik algoritma (GA), diferansiyel evrim (DE) ve parçacık sürü optimizasyonu (PSO) gibi çok bilinen diğer algoritmalara oranla, yapay arı kolonisi algoritması oldukça basit, güçlü ve az sayıda kontrol parametreleri içeren bir optimizasyon metodudur [29, 30]. Yapay arı kolonisi algoritmasında işçi arılar, gözcü arılar ve kâşif arılar olmak üzere üç tip arı grubu bulunmaktadır [3]. Algoritmanın temel işleyişi üç ana adımdan oluşur. İlk adımda işçi arılar kaynaklara gönderilir ve nektar miktarları hesaplanır. İkinci 
adımda, eşzamanlı olarak gözcü arılar işçi arılardan aldıkları bilgilere göre kaynak seçimi yapar ve nektar miktarı hesaplanır. Son adımda ise rastgele yeni kaynakların bulunması için kâşif arılar görevlendirilir [17]. Gözcü arının bir yiyecek kaynağını tercih etme ihtimali, p p, Eş. 11 ile tanımlanmaktadır [31].

$p_{i}=\frac{f i t_{i}}{\sum_{n=1}^{S N} f i t_{n}}$

Burada, fiti, $i$. çözüme ait uygunluk değeri yani $i$. pozisyondaki yiyecek kaynağının nektar miktarını göstermektedir. Eş. 12'den yararlanarak çözümlerin uygunluk değeri bulunur [32].

$$
f i t_{i}= \begin{cases}\frac{1}{1+f_{i}} & \text { eğer } f_{i} \geq 0 \\ 1+a b s\left(f_{i}\right) & \text { eğer } f_{i}<0\end{cases}
$$

İşçi ve gözcü arıların hafizalarında kayıtlı bulunan yiyecek kaynağının komşuluğunda üretecekleri yeni yiyecek kaynağına ait pozisyon Eş. 13 ile ifade edilir [31].

$$
v_{i j}=x_{i j}+\phi_{i j}\left(x_{i j}-x_{k j}\right)
$$

Yukarıdaki denklemde SN işçi arı sayısına eşit olan yiyecek kaynağının sayısı ve $D$ optimizasyon parametrelerinin sayısı olmak üzere; $k \in\{1,2, \ldots, \mathrm{SN}\}$ ve $\mathrm{j} \in\{1,2, \ldots, \mathrm{D}\}$ rastgele seçilen indislerdir ve $k$ indisi rastgele üretilmesine rağmen $i$ indisinden farklı olmalıdır. $\phi_{\mathrm{ij}}[-1,1]$ aralığında rastgele üretilen bir sayıdır [3].

\subsection{Hibrit Yaklaşım (Hybrid Approach)}

$\mathrm{ABC}$ algoritması analizinden anlaşılacağı üzere temel $\mathrm{ABC}$ algoritması popülasyonun global en iyi çözümünü doğrudan kullanmadığı görülmektedir. Ayrıca PSO'daki parçacıklar yerel minimuma sıkıştığında, temel PSO modellerinin yerel minimumdan kurtulmalarını sağlayacak herhangi bir yetisi yoktur. Bu iki algoritmanın dezavantajları ile baş edebilmek amacıyla yeniden birleşim (recombination) prosedürüne dayalı hibrit bir global optimizasyon yaklaşımı Kıran tarafından önerilmiştir [22].Yeniden birleşim ya da genetik değişim, evrim operatörü olarak bilinir ve TheBest adında yeni bir çözüm üretmek için kullanılır. TheBest, PSO için gbest olarak alınırken ABC için gözlemci arıların komşusu olarak alınır. TheBest'i elde edebilmek için, PSO'nun gbest'inin ve $\mathrm{ABC}$ 'nin en iyi çözümünün (best) uygunluk değerleri Eş. 12 kullanılarak hesaplanır iken iki çözümün seçim olasılıkları ise bu uygunluk değerleri ile Eş.14 ve Eş. 15 birlikte kullanılarak hesaplanır [22].

$p_{\text {best }}=\frac{f i t_{\text {best }}}{f i t_{\text {gbest }}+f i t_{\text {best }}}$

$$
p_{\text {gbest }}=\frac{f i t_{\text {gbest }}}{f i t_{\text {gbest }}+f i t_{\text {best }}}
$$

Burada $p_{\text {best }} A B C$ 'nin en iyi çözümünün seçim olasılı̆̆g, $p_{\text {gbest }}$ PSO'nun gbest'i, fit gbest ve fit ${ }_{\text {best }}$ ise sirasıyla Eş. 12 ile elde edilen PSO'nun gbest'inin ve ABC'nin en iyi çözümünün uygunluk değerleridir [22]. TheBest oluşturulurken, [0,1] aralığındaki rastgele sayılar problemin boyutu için kullanılır. Eğer rastgele sayı $p_{\text {best }}$ 'ten küçük ya da ona eşitse bu boyut için değer $\mathrm{ABC}$ 'nin en iyi çözümünden (best) alınır; aksi takdirde bu boyut için değer PSO'nun gbest'inden alınır [22]. Bu Eş. 16 ile formüle edilir [22].

TheBest $_{i}= \begin{cases}\text { best }_{i} & \text { eğer }\left(r \leq p_{\text {best }}\right) \\ \text { gbest }_{i} & \text { diğer durumda }\end{cases}$

Burada TheBest $\mathrm{i}_{\mathrm{i}}$, TheBest' in $i$. boyutudur; best $\mathrm{ABC}_{\mathrm{i}}$ 'nin arı popülasyonunun çalışmasıyla elde edilen en iyi çözümün $i$. boyutudur, gbest $\mathrm{i}_{\mathrm{i}}$ ise PSO'nun gbest'inin $i$. boyutudur. Yeniden birleşme prosedürü kullanılarak, HPA içindeki parçacıklar (particles) ve arıların (bees) arasındaki ilişki sağlanır. HPA'nın sosyal bileşeni "TheBest" olup bu kullanılmak suretiyle global en iyi bilginin doğrudan kullanımıyla sadece ABC'nin yararlanma (exploitation) yetisi geliştirilmiş olmaz aynı zamanda PSO'nun yerel minimumdan kurtulma yetisi de geliştirilmiş olur [22]. PSO'nun gbest'i TheBest ile değiştirilir ve TheBest ABC'nin gözlemci arılarına komşu olarak atanır. Şekil 1'de HPA'nın akış diyagramı verilmiştir. HPA da PSO ve ABC gibi iteratif bir algoritma türüdür ve sonlandırma koşulu maksimum iterasyon sayısı, maksimum çalışma süresi vb. olabilir [22].

\section{4. ÖNERILEN TASARIM YÖNTEMI (PROPOSED DESIGN METHODOLOGY)}

\subsection{PSS Yapisl (PSS Structure)}

PSS düşük frekanslı salınımları etkin bir şekilde söndürmede kullanılan kararlı kılıcı bir cihazdır. Basit yapısı ve uygulama kolaylığı olmasından dolayı literatürde çokça tercih edilen faz ilerlemeli-gerilemeli kontrolörün fonksiyonel blok diyagramı Şekil 2'de verilmiştir [21, 23]. Şekilde $\Delta \omega$ hız sapması ve $\mathrm{V}_{S}$ ise kararlı kılıcı çıkış işaretidir. $K_{P}$ kararlı k1lıcı kazanç sabiti, PSS tarafından enjekte edilen sönümleme miktarını belirler. Temizleme bloku temel yüksek geçiren filtre görevi görüp ve $T_{W}$ zaman sabitinin değeri $\quad 0,5-20 \quad \mathrm{~s}$ aralığında olmaktadır [33]. Faz kompanzasyonu zaman sabitleri ise $\mathrm{T}_{1}, \mathrm{~T}_{2}, \mathrm{~T}_{3}$ ve $\mathrm{T}_{4}$ ' dir [33].

\subsection{Amaç Fonksiyonu ve PSS Ayarlanması (Objective function and PSS tuning)}

Güç sisteminin kararlılı̆̆ özdeğerlerine bakılarak karar verilebilmektedir. Büyük negatif reel kısımlı özdeğerler $(\sigma)$, sistemin yerleşme zamanını azaltarak daha hızlı kararlı davranış göstermesini 


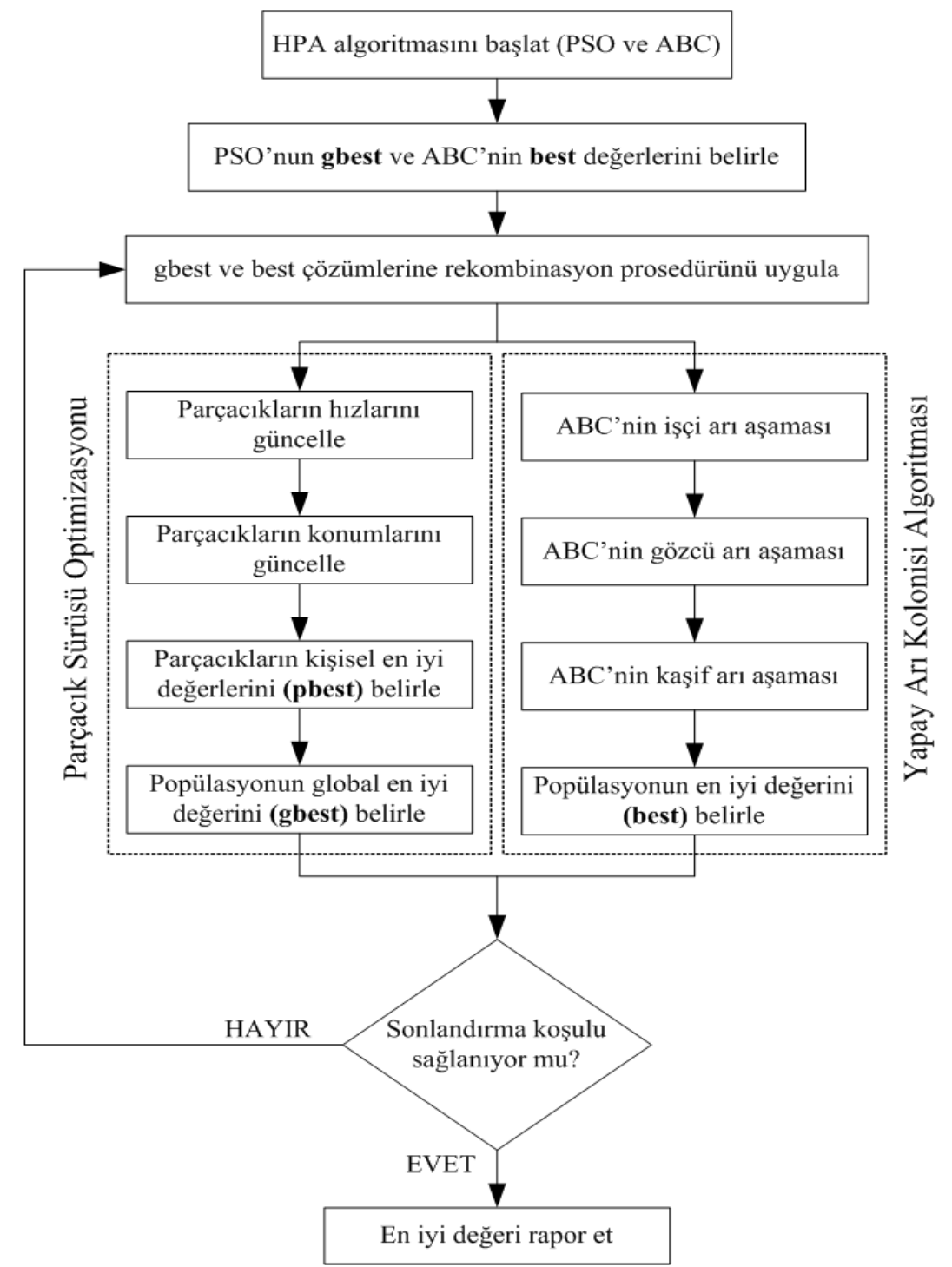

Şekil 1. HPA akış diyagramı (Flowchart of the HPA) [22]

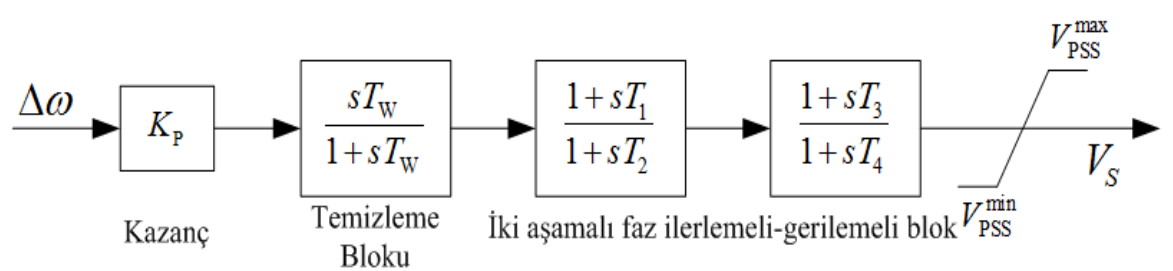

Şekil 2. PSS'nin blok diyagramı (Block diagram of PSS)

sağlar. Bununla birlikte maksimum aşım ve salınım

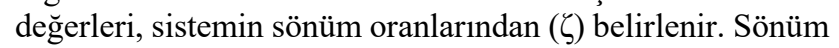
oranında yapılan herhangi bir artış, sistemin kararlılığının düzeltilmesine sebep olur. Bu iki kriteri göz önüne alarak, bu

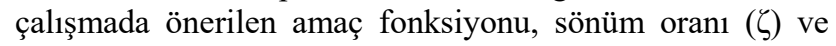
özdeğerlerin reel kısmının $(\sigma)$ bir kombinasyonu olarak alındı. Önerilen özdeğer tabanlı amaç fonksiyonu aşağıdaki gibidir ve bunun minimum olması istenir [2].

$$
\begin{aligned}
& J_{1}=\sum_{i=1}^{k}\left(\sigma_{i}-\sigma_{0}\right)^{2} \text { ve } \sigma_{i} \leq \sigma_{0} \quad\left(\sigma_{0}=-1\right) \\
& J_{2}=\sum_{i=1}^{k}\left(\zeta_{i}-\zeta_{0}\right)^{2} \text { ve } \zeta_{i} \geq \zeta_{0} \quad\left(\zeta_{0}=\% 10\right) \\
& J=J_{1}+\alpha J_{2}(\alpha=10)
\end{aligned}
$$


Eş. 17, Eş. 18 ve Eş. 19'da, $k$ lineerleştirilmiş örnek güç sisteminin toplam özdeğer sayısını, $\sigma$ ve $\zeta$ sirasıyla $i$. özdeğerin reel kısmını ve sönüm oranını göstermektedir. $\sigma_{0}$ ve $\zeta_{0}$ tasarım için seçilen eşik değerler olup sırasıyla -1 ve \%10 olarak alınmıştır. $J$ amaç fonksiyonunu minimum hale getirme gayemiz, sistem cevabının yerleşme zamanını ve aşımını iyileştirmektir. $\mathrm{J}_{1}, \quad \mathrm{~J}_{2}$ ve $\mathrm{J}=\mathrm{J}_{1}+\alpha \mathrm{J}_{2}$ amaç fonksiyonlarının tanım bölgesi Şekil 3 'te verilmiştir. $J$ amaç fonksiyonundaki $\mathrm{J}_{1}$ terimi, özdeğerlerin reel kısmını kontrol eder ve genellikle sistem özdeğerlerini $\sigma_{0}$ 'dan küçük olan bölgedeki imajiner eksenin sol tarafina iteler (Şekil 3a). Benzer şekilde $J$ amaç fonksiyonundaki $\mathrm{J}_{2}$ terimi, özdeğerlerin sönüm oranını istenilen sönüm oranına $\left(\zeta_{0}\right)$ getirir ve sistemin aşımını kontrol eder (Şekil 3b). Yapılan denemeler sonucunda $\alpha$ katsayısının değeri 10 olarak alınması uygun görülmüştür [2]. Tasarım problemi için PSS sistem parametrelerinin sınırlarının belirlenmesi zorunludur ve bu kısıtlamalar Eş. 21 ve Eş. 22'deki gibidir [6].

$$
0.1 \leq K_{P} \leq 100
$$

$0.01 \leq T_{i} \leq 1 \quad ; i=1,2,3,4$ için

Önerilen tasarım yaklaşımı, HPA tekniğini kullanmak suretiyle optimizasyon problemindeki $\mathrm{J}=\mathrm{J}_{1}+\alpha \mathrm{J}_{2}$ amaç fonksiyonunu minimum hale getirerek optimal PSS sistem parametrelerini $\left(K_{P}, T_{1}, T_{2}, T_{3}\right.$ ve $\left.T_{4}\right)$ bulmaya çalışır. HPA algoritmasını kullanmak amacıyla MATLAB program dilinde bir yazılım geliştirilmiş ve PSS ilave edilmiş güç sisteminin lineerleştirilmiş modeli üzerinden optimizasyon yapılmıştır.

\section{SONUÇLAR VE TARTIŞMALAR (RESULTS AND DISCUSSIONS)}

Bu çalışmada; yük akışı analizi, küçük işaret kararlılık analizi ve optimizasyonu problemi ile PSS tasarımı için MATLAB $m$-file ve geçici hal kararlığı analizi için Simulink tabanlı etkili ve güçlü detaylı model geliştirilmiştir. Ayrıca, PSO tabanlı PSS (PSOPSS), ABC tabanlı PSS (ABCPSS) ve önerilen hibrit tabanlı PSS (HPAPSS) bazı analizler yapılarak karşılaştırmalı olarak incelenmiştir.

\subsection{Test Sistemi ve Optimum PSS Yeri \\ (Test System and Optimum PSS Location)}

Bu çalışmada, empedans diyagramları ile birlikte Şekil 4'te verilen 3-makinalı 9-baralı güç sistemi [23, 34] ele alındı. Her bir generatör dördüncü mertebeden lineer olmayan modelle gösterildi. $\mathrm{Bu}$ güç sistemine ilişkin bara, hat, generatör ve uyarma verilerinin düzenlenmiş hali [35]'te ayrıntılı olarak verilmiştir. Kararlı kılıcısı tasarımındaki en önemli adım, PSS yerleri için en etkili generatörleri belirlemektir. Katılım faktörü metodu, optimum PSS yerlerini bulmak için güç sistemlerinde oldukça yaygın kullanılmaktadır [13]. PSS'siz sistem için nominal çalışma noktası civarında lineerleştirme prosedürü uygulandı ve 12x12 büyüklüğünde $\mathbf{A}_{\text {sys }}$ sistem matrisi elde edildi. Sönümün sıfır olmasından $(\mathrm{D}=0)$ dolayı iki adet sıfır özdeğer elde edildi. Kontrolsüz sistemin tüm özdeğerlerine ilişkin katılım faktörleri Tablo 1'de verildi. Sadece katılım faktörü değeri 0,2'den büyük olanlar listelendi. Durum değişkenleri ve bu durum değişkenlerine ilişkin makinalar da gösterildi. Kalın ile yazılan özdeğerler, elektromekanik salınım mod özdeğerlerini belirtmektedir. Özdeğerlerden anlaşılacağ üzere sistem sönümü çok düşük ve sistem oldukça salınımlı cevap sergilemektedir. $\mathrm{Bu}$ nedenle sistemin dinamik performansını iyileştirmek amacıyla bir veya daha çok sayıda PSS yerleştirilmelidir. Katılım faktörü metodu kullanımı ile oluşturulan tablo, salınımların yerel modlarını sönümlemek için yalnızca 2 nolu generatöre $\left(G_{2}\right)$ PSS yerleştirilmesini yeterli görmektedir.

\subsection{HPA Tabanlı PSS Tasarımı ve Özde ğer Analizi (HPA-based PSS Design and Eigenvalue Analysis)}

$\mathrm{Bu}$ makalede, örnek sistem için yalnızca $\mathrm{G}_{2}$ için PSS tasarlanacağından dolayı optimize edilecek parametre sayıs1 5'tir. Optimizasyon problemini çözebilmek ve kararlı k1lıcının parametrelerinin en uygun değerlerini belirlemek için HPA algoritması, örnek güç sisteminin lineerleştirilmiş modeli kullanılarak MATLAB programında çalıştırıldı. Ayrıca, kararlı kılıcının parametre optimizasyonu için önerilen hibrit algoritmanın dinamik kararlılık performansını ve üstünlüğünü belirgin şekilde göstermek için diğer iki algoritma tabanlı PSS'ler (PSOPSS ve ABCPSS) ile karşılaştırma yapıldı.

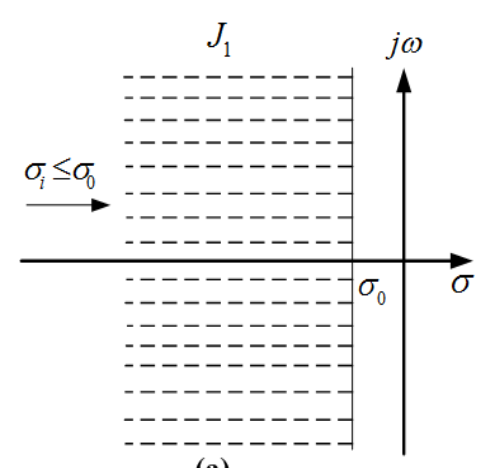

(a)

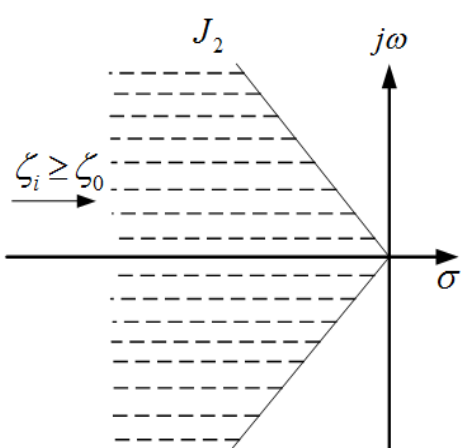

(b)

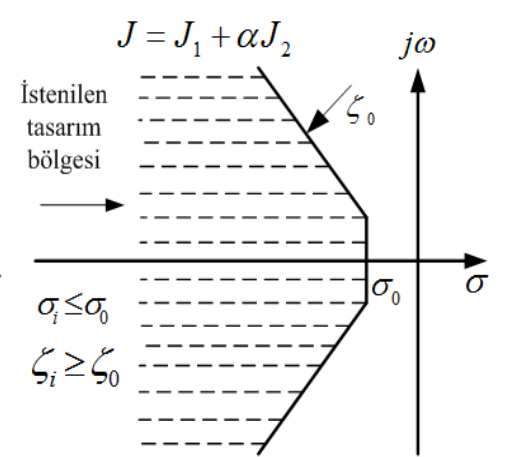

(c)

Şekil 3. Amaç fonksiyonunun bölgesi (Region of objective function) 


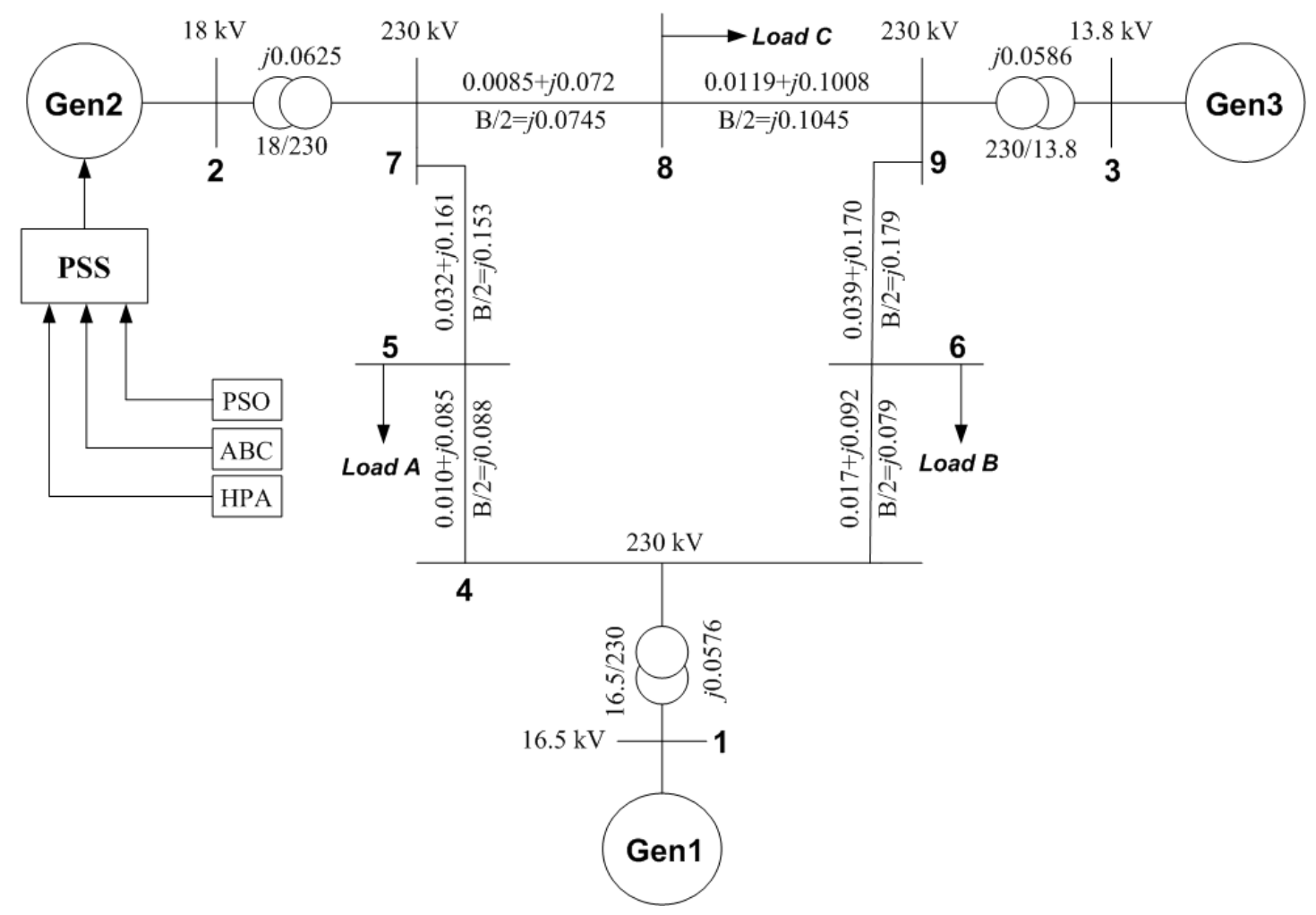

Şekil 4. Çok makinalı test sistemi (Multi-machine test system)

Tablo 1. Özdeğerler ve katılım faktörleri (Eigenvalues and their participation factors)

\begin{tabular}{|c|c|c|c|c|}
\hline Özdeğer & Sönüm Oranı & Makina numarası & Makina değişkeni & Katılım Faktörü \\
\hline \multirow{2}{*}{$-0,3831 \pm 7,8846 \mathrm{i}$} & \multirow{2}{*}{0,0485} & 2 & $\delta, \omega$ & 1,00 ve 1,00 \\
\hline & & 1 & $\delta, \omega$ & 0,46 ve 0.46 \\
\hline \multirow{2}{*}{$-1,3738 \pm 11,7499 \mathrm{i}$} & \multirow{2}{*}{0,1161} & 3 & $\delta, \omega$ & 1,00 ve 1,00 \\
\hline & & 2 & $\delta, \omega$ & 0,24 ve 0,24 \\
\hline \multirow{3}{*}{$-9,8638 \pm 13,6643 \mathrm{i}$} & \multirow{3}{*}{0,5853} & 1 & $\mathrm{E}_{\mathrm{q}}^{\prime}, \mathrm{E}_{\mathrm{fd}}$ & 1,00 ve 0,99 \\
\hline & & 2 & $\mathrm{E}_{\mathrm{q}}^{\prime}, \mathrm{E}_{\mathrm{fd}}$ & 0,89 ve 0,86 \\
\hline & & 3 & $\mathrm{E}_{\mathrm{q}}^{\prime}, \mathrm{E}_{\mathrm{fd}}$ & 0,75 ve 0,73 \\
\hline \multirow{2}{*}{$-9,9194 \pm 6,4142 \mathrm{i}$} & \multirow{2}{*}{0,8397} & 1 & $E_{\mathrm{q}}^{\prime}, \mathrm{E}_{\mathrm{fd}}$ & 1,00 ve 0,98 \\
\hline & & 2 & $\mathrm{E}_{\mathrm{q}}^{\prime}, \mathrm{E}_{\mathrm{fd}}$ & 0,59 ve 0,57 \\
\hline \multirow{2}{*}{$-12,7012$} & \multirow{2}{*}{1,0000} & 3 & $\mathrm{E}_{\mathrm{fd}}, \mathrm{E}_{\mathrm{q}}^{\prime}$ & 1,00 ve 0,60 \\
\hline & & 2 & $\mathrm{E}_{\mathrm{fd}}, \mathrm{E}_{\mathrm{q}}^{\prime}$ & 0,48 ve 0,29 \\
\hline \multirow{2}{*}{$-5,5006$} & \multirow{2}{*}{1,0000} & 3 & $\mathrm{E}_{\mathrm{q}}^{\prime}, \mathrm{E}_{\mathrm{fd}}$ & 1,00 ve 0,36 \\
\hline & & 2 & $\mathrm{E}_{\mathrm{q}}^{\prime}$ & 0.39 \\
\hline \multirow{2}{*}{0,0000} & \multirow{2}{*}{---- } & 1 & $\delta, \omega$ & 1,00 ve 1,00 \\
\hline & & 2 & $\delta, \omega$ & 0,28 ve 0,28 \\
\hline \multirow{2}{*}{0,0000} & \multirow{2}{*}{---- } & 1 & $\delta, \omega$ & 1,00 ve 1,00 \\
\hline & & 2 & $\delta, \omega$ & 0,28 ve 0,28 \\
\hline
\end{tabular}


Şekil 5'teki akış diyagramından görüleceği gibi Eş. 19'da verilen özdeğer tabanlı amaç fonksiyonunun her bir iterasyondaki değeri hesaplanır ve maksimum iterasyon sayısına (iter $\max =40)$ ulaşıldı̆̆ında ise en uygun PSS parametreleri bulunmak suretiyle optimizasyon süreci bitirilmiş olur. Optimizasyon süreci sonunda $\mathrm{PSO}, \mathrm{ABC}$ ve HPA algoritmaları kullanılarak elde edilen en uygun PSS parametreleri Tablo 2'de verilmiştir. Özdeğer tabanlı amaç fonksiyonunun iterasyon sayısına göre değişimi Şekil 6'da verilmiştir. Amaç fonksiyonunun değişimi grafiğine bakıldığında, PSO algoritması ile 34. iterasyonda ABC algoritmas1 ile 29. iterasyonda ve son olarak önerilen hibrit algoritma ile 21. iterasyonda yakınsama olur. İterasyon sayısına göre en yüksek yakınsama hızı HPA algoritmasında meydana gelir. Kontrolsüz sistem ile kontrolör parametreleri optimize edilen kontrollü sistemlerin (PSOPSS, ABCPSS ve HPAPSS) elektromekanik salınım özdeğerleri ve bu özdeğerlere karşılık gelen sönüm oranları Tablo 3'te gösterilmiştir. Kontrolsüz sistemin en düşük sönüm oranı 0,0485 olduğu için sistem yüksek salınımlı bir davranış gösterir. En düşük sönüm oranı PSOPSS ile 0,1610; ABCPSS ile 0,2359 ve en iyi sönümleme sağlayan HPAPSS ile 0,2812 olmaktadır. Ayrica HPAPSS ile özdeğerlerin reel kısmı diğer iki yöntemle bulunan özdeğerlere göre sdüzlemin daha solunda bulunmaktadır. Özdeğer analizinden anlaşılacağı üzere; önerilen hibrit tabanlı PSS (HPAPSS), PSO ve ABC ile optimize edilen sistemlere (PSOPSS ve ABCPSS) göre daha yüksek performans göstermektedir ve elektromekanik modların sistem sönümü ile yerleştirme zamanını dikkate değer ölçüde iyileştirmektedir. Üç algoritma ile özdeğer tabanlı amaç fonksiyonu minimum hale getirilerek sonlandırılan optimizasyon süreci için geçen süreler Tablo 4'te verilmiştir. Tablodan görüleceği gibi 3makinalı 9-baralı güç sistemi için HPA algoritması kullanılarak bulunan hesaplama zamanı, diğer iki algoritma ile bulunan hesaplama zamanına göre daha az çıkmaktadır. Böylece HPA metodu ile çalışan sistemler önemli ölçüde zaman tasarrufu sağlar ve bu nedenle yüksek hızlı işlemcili online optimizasyonlar için kullanılması da mümkündür.

\subsection{Lineer Olmayan Simülasyon Sonuçları (Nonlinear Simulation Results)}

\subsubsection{Simulink modeli (Simulink model)}

Lineer olmayan güç sisteminin zaman domeninde analizi, güçlü modelleme ve etkili bir simülasyon aracı olan Simulink programının çeşitli blokları yardımıyla oluşturulan bir model üzerinden yapıldı. Güç sistemine ilişkin (1)-(7) denklemlerini kullanarak 3-makinalı 9-baralı test sistemi için geliştirilen lineer olmayan simülasyon modeli Şekil 7'de detaylı olarak verilmiştir. Şekil 7'den görüleceği üzere Subsystem 1, 2 ve 3, örnek güç sisteminin tüm makinalarına ilişkin diferansiyel denklemler alt modellerini; Subsystem 4, 5 ve 6 , tüm makinalara ilişkin stator cebirsel denklemler alt modellerini ve Subsystem 7, 8 ve 9 ise tüm makinalara ilişkin şebeke denklemleri alt modellerini göstermektedir. Ayrıca Simulink tabanlı bu model, geçici hal kararlılık çalışmaları yapan tüm öğrenci ve araştırmacılara faydalı olup bu model üzerinde çeşitli simülasyon parametrelerinin değişimi ve seçimi de kolaylıkla yapılabilir.

\subsubsection{Durum çalışmaları (Case studies)}

Önerilen HPA tabanlı PSS'nin etkinliği ile PSO ve ABC tabanlı diğer PSS'lere üstünlügünü belirlemek için iki farklı büyük arıza senaryosu göz önüne alınarak lineer olmayan zaman domeni simülasyonları yapıldı. Tüm senaryo durumlarında, örnek sistem için en ciddi arıza yeri olan 7 nolu baraya yakın 5-7 hattı sonunda üç fazlı bir arızanın olduğu dikkate alındı [21]. Arızalı 5-7 hattı yeniden devreye sokularak sistemdeki arıza giderildi.

Senaryo 1: $\mathrm{t}=1 \mathrm{~s}$ anında arıza olduğu ve arıza temizleme süresinin $0,10 \mathrm{~s}$ (6 devir) olduğu düşünüldü. $\mathrm{Bu}$ ciddi arıza altında, Şekil 8 ile 9 sirasıyla $\delta_{2}-\delta_{1}$ ve $\delta_{3}-\delta_{1}$ bağıl güç açı cevaplarını ve Şekil 10 ile 11 ise sırasıyla $\omega_{2}-\omega_{1}$ ve $\omega_{3}-\omega_{1}$ bağıl hız sapmalarını göstermektedir. Şekillerden kontrolsüz sistemin yeterli olarak sönümlenmediği ve çok aşım yaptı̆̆ 1 görülmekte iken sezgisel optimizasyon teknikleri ile optimize edilen sistemlerin (PSOPSS, ABCPSS ve HPAPSS) kararlılık performansı, güç açıları ve hızlarındaki salınımları önemli ölçüde kısıtladıkları için oldukça iyi görülmektedir. Bununla birlikte şekillerden açıkça görüleceği üzere, bu çalışmada önerilen hibrit algoritma tabanlı PSS (HPAPSS); PSOPSS ve ABCPSS'ye nazaran güç sistemi salınımlarını etkin olarak bastırabilmekte ve sistemi daha hızlı kararlı yapabilmektedir.

Senaryo 2: $\mathrm{t}=1 \mathrm{~s}$ anında arıza olduğu ve arıza temizleme süresinin $0,20 \mathrm{~s}$ (12 devir) olduğu düşünüldü. Bu senaryo durumu için sistem cevapları Şekil $12-15$ 'de verilmiştir. Arıza temizleme süresinin iki katına çıkması durumunda şekillerden görüleceği gibi kontrolsüz sistem kararsızlığa sürüklenmektedir. Buna rağmen kararlı kılıcının parametreleri PSO, ABC ve HPA ile optimize edilen sistemler, bu ciddi arıza durumda bile kararlılığını korumaktadır. Ayrıca, bu büyük arıza senaryosu altında HPAPSS daha az aşım yaparak ve geçici hal hatalarını minimum hale getirerek sistemi çabucak kararlı yaptığından dolayı PSOPSS ve ABCPSS sistemlerine oranla daha iyi bir dinamik performans göstermektedir.

\subsubsection{Kritik temizleme zamanı (Critical clearing time)}

Senkron generatörlerde kritik temizleme zamanı, sistemi kararsızlığa götürmeden meydana gelen arızayı temizlemek için izin verilen maksimum zaman aralığı olarak ifade edilir [35]. Lineer olmayan zaman domeni simülasyonlarında kritik temizleme zamanı, güç sisteminin geçici hal kararlılığını etkileyen en önemli faktörlerden biridir [21, 35]. Kritik temizleme zamanı yüksek olan sistemler daha kararlıdır ve ciddi arıza durumlarında bile senkronizasyonlarını kaybetmeyebilirler. 5-7 hattının kritik temizleme zamanı, sistemin hem kontrolsüz çalışması hem de PSO, ABC ve HPA algoritmalarıly optimize edilen PSS kullanılarak kontrollü çalışması durumları için Tablo 5'te verilmiştir. 


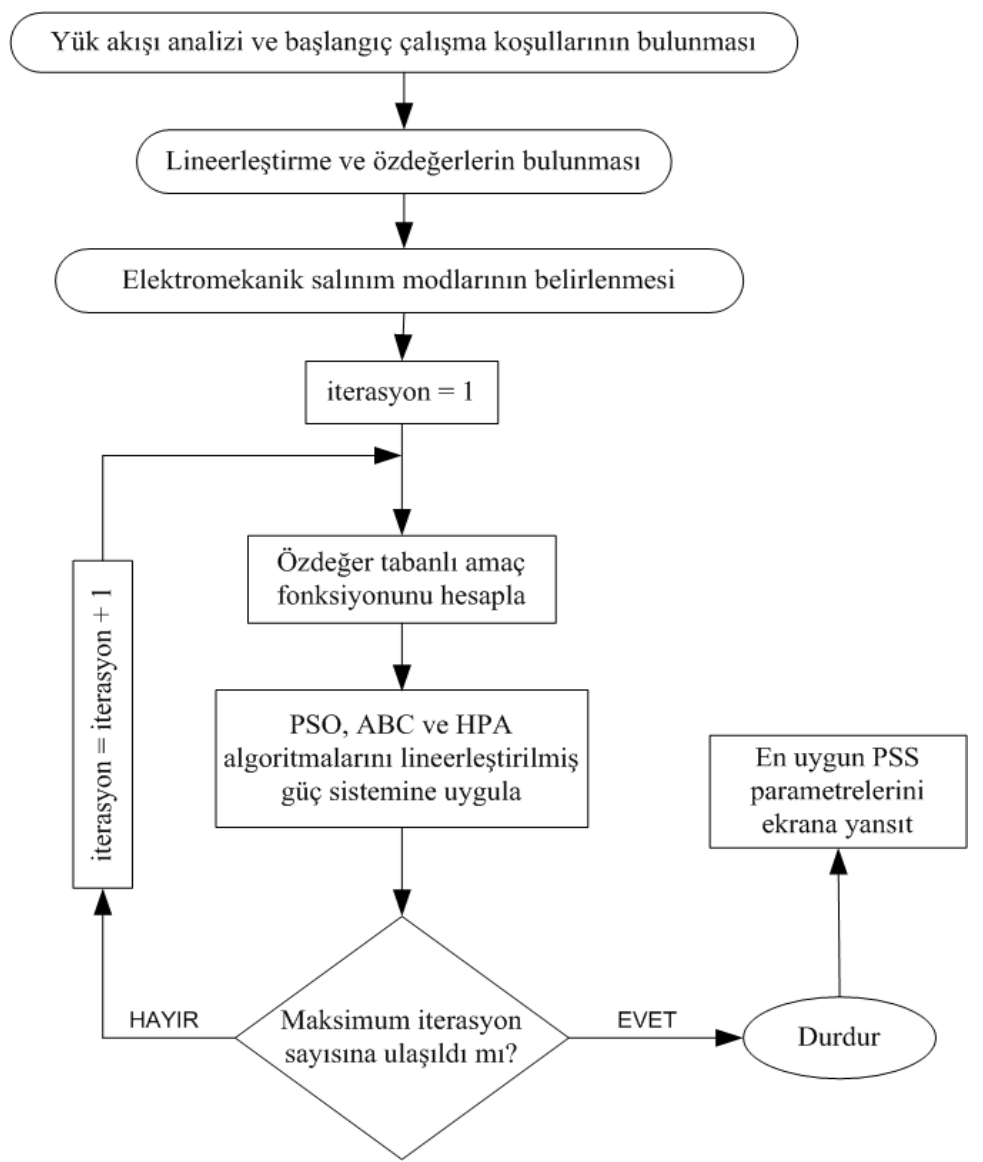

Şekil 5. Optimizasyon sürecinin akış diyagramı (Flowchart of optimization process)

Tablo 2. En uygun PSS parametreleri (The optimal PSS parameters)

\begin{tabular}{llllll}
\hline Metot & $\mathrm{K}_{\mathrm{P}}$ & $\mathrm{T}_{1}$ & $\mathrm{~T}_{2}$ & $\mathrm{~T}_{3}$ & $\mathrm{~T}_{4}$ \\
\hline PSO & 13,9341 & 0,1072 & 0,9604 & 0,7490 & 0,0100 \\
ABC & 26,8082 & 0,3341 & 0,2663 & 0,2566 & 0,0100 \\
HPA & 5,0788 & 0,6887 & 0,0148 & 0,5806 & 0,5632 \\
\hline
\end{tabular}

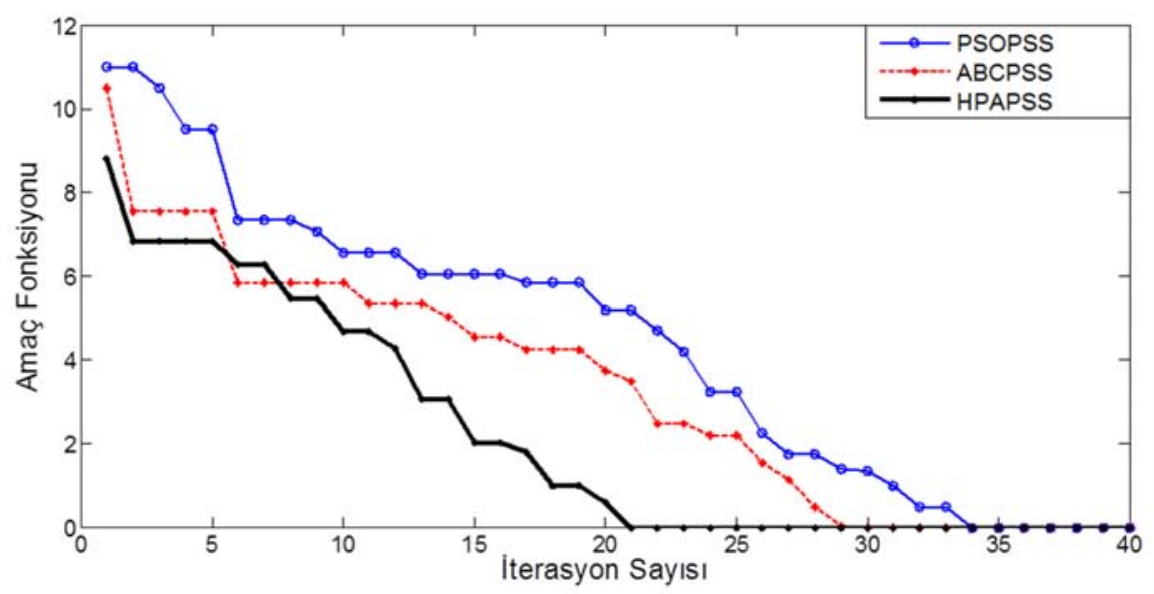

Şekil 6. Amaç fonksiyonunun yakınsama hızı (Convergence rate of the objective function) 
Tablo 3. Elektromekanik modların özdeğerleri ve sönüm oranları (Eigenvalues of electromechanical modes and damping ratios)

\begin{tabular}{lll}
\hline Metot & Özdeğerler & Sönümler \\
\hline Kontrolsüz sistem & $-0,3831 \pm 7,8846 \mathrm{i}$ & 0,0485 \\
(Without PSS) & $-1,3738 \pm 11,7499 \mathrm{i}$ & 0,1161 \\
PSO ile optimize edilen sistem & $-2,1240 \pm 13,0167 \mathrm{i}$ & 0,1610 \\
(PSOPSS) & $-1,7668 \pm 8,1986 \mathrm{i}$ & 0,2107 \\
ABC ile optimize edilen sistem & $-2,4971 \pm 10,2878 \mathrm{i}$ & 0,2359 \\
(ABCPSS) & $-2,1924 \pm 6,2926 \mathrm{i}$ & 0,3290 \\
HPA ile optimize edilen sistem & $-3,1273 \pm 10,6730 \mathrm{i}$ & 0,2812 \\
(HPAPSS) & $-2,2671 \pm 5,5054 \mathrm{i}$ & 0,3808 \\
\hline
\end{tabular}

Tablo 4. PSO, ABC ve HPA algoritmaları için hesaplama zamanı (Computation time for PSO, ABC and HPA algorithms)

\begin{tabular}{llll}
\hline Algoritma türü & PSO & ABC & HPA \\
\hline Geçen süre (s) & 21,49 & 19,84 & 18,26 \\
\hline
\end{tabular}

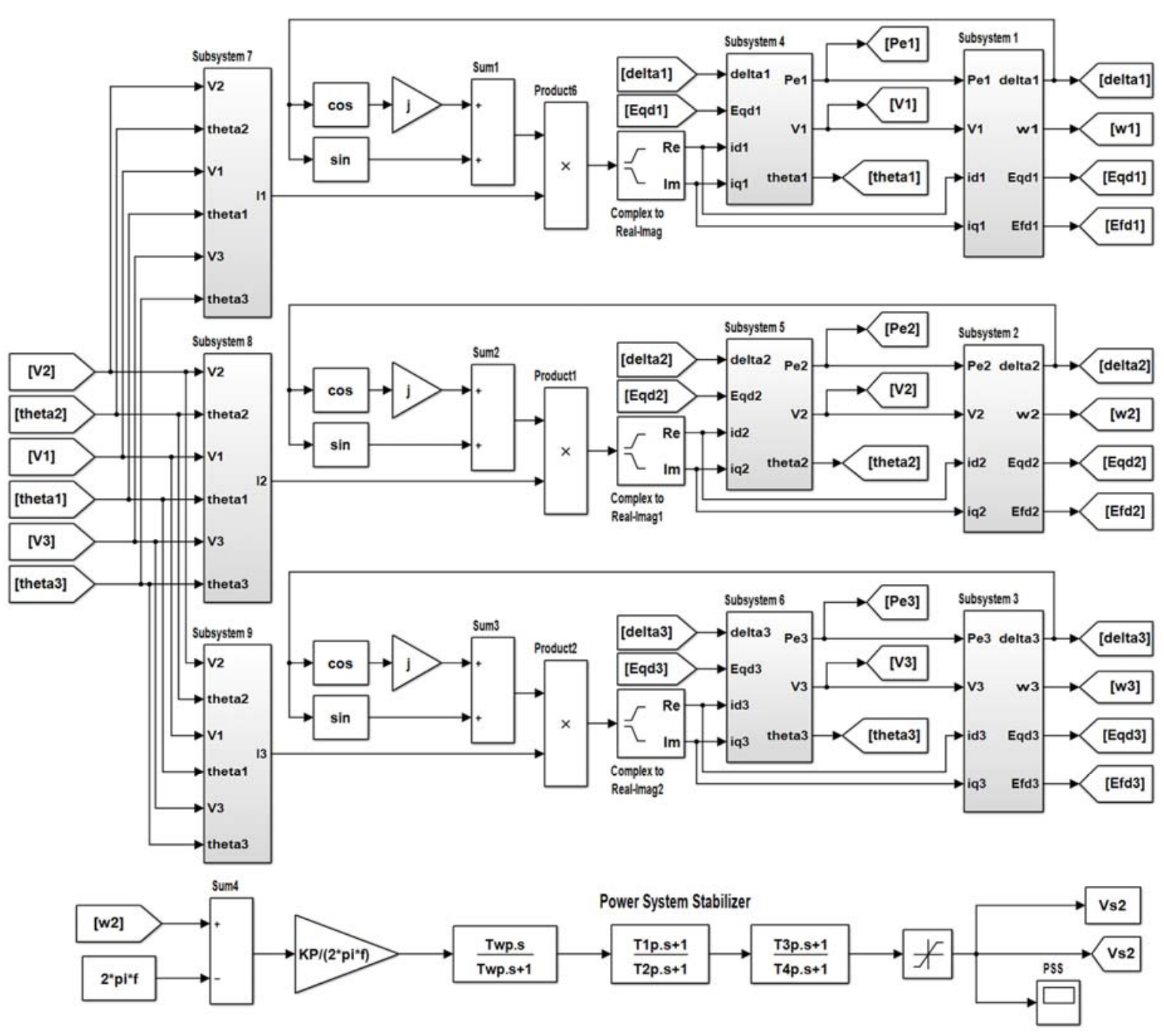

Şekil 7. 3-makinalı 9-baralı güç sisteminin Simulink modeli (Simulink model of 3-machine, 9-bus power system) 


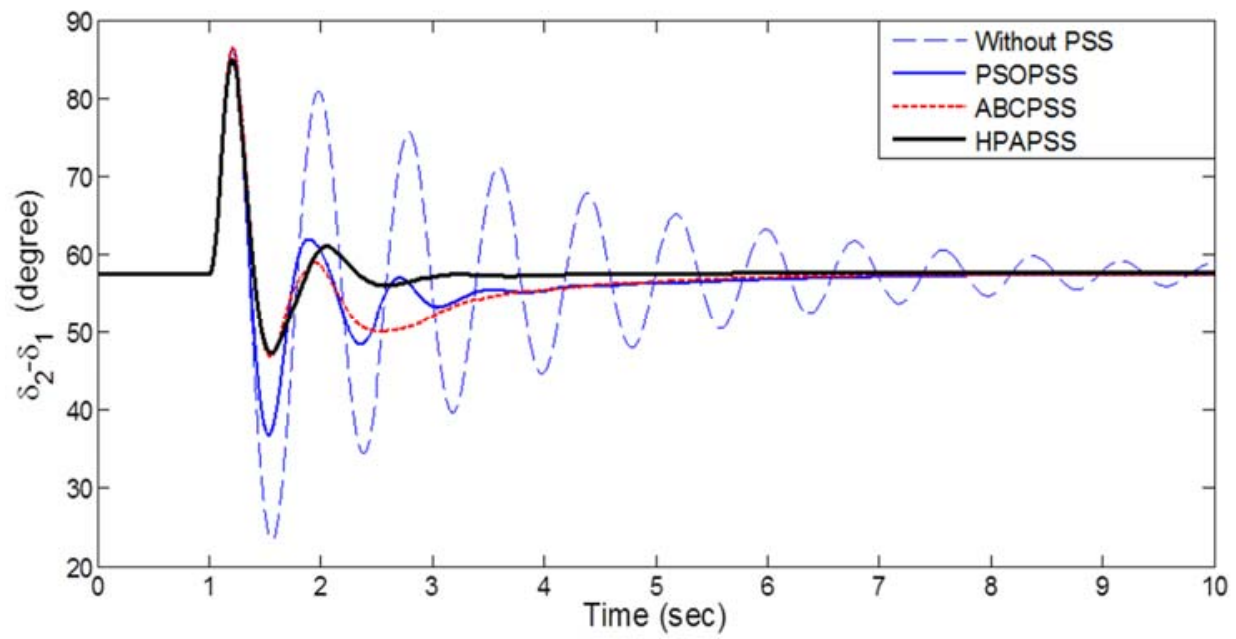

Şekil 8. Senaryo 1 için $\delta_{2}-\delta_{1}$ 'in cevab1 (Response of $\delta_{2}-\delta_{1}$ for scenario 1 )

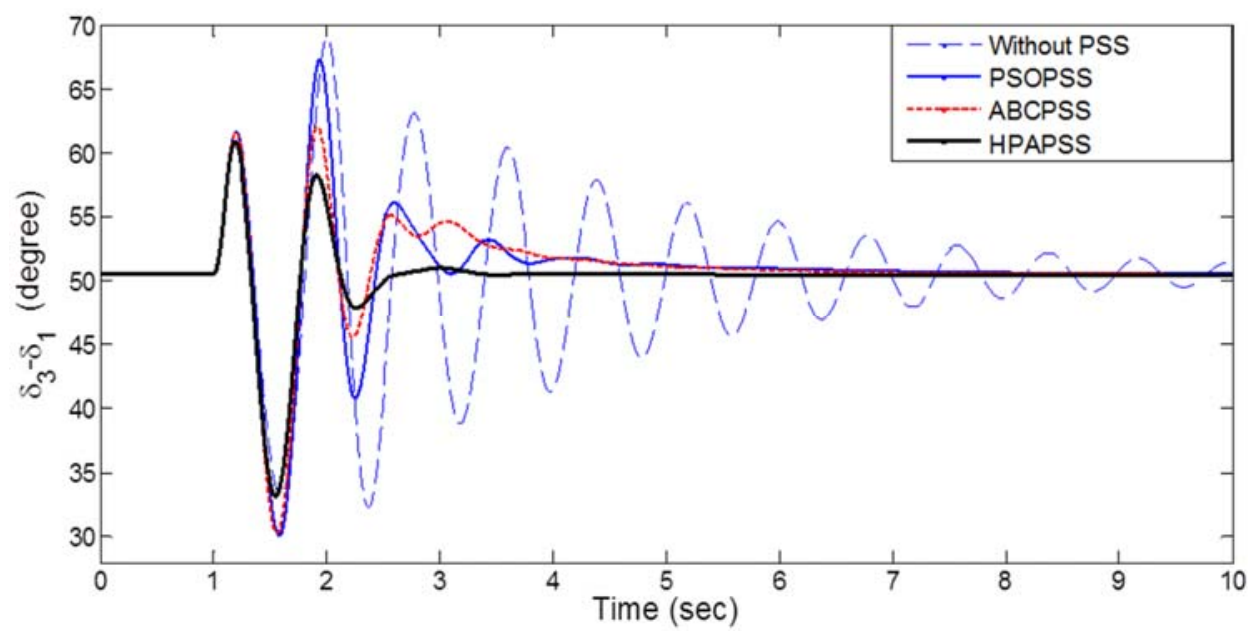

Şekil 9. Senaryo 1 için $\delta_{3}-\delta_{1}$ 'in cevab1 (Response of $\delta_{3}-\delta_{1}$ for scenario 1 )

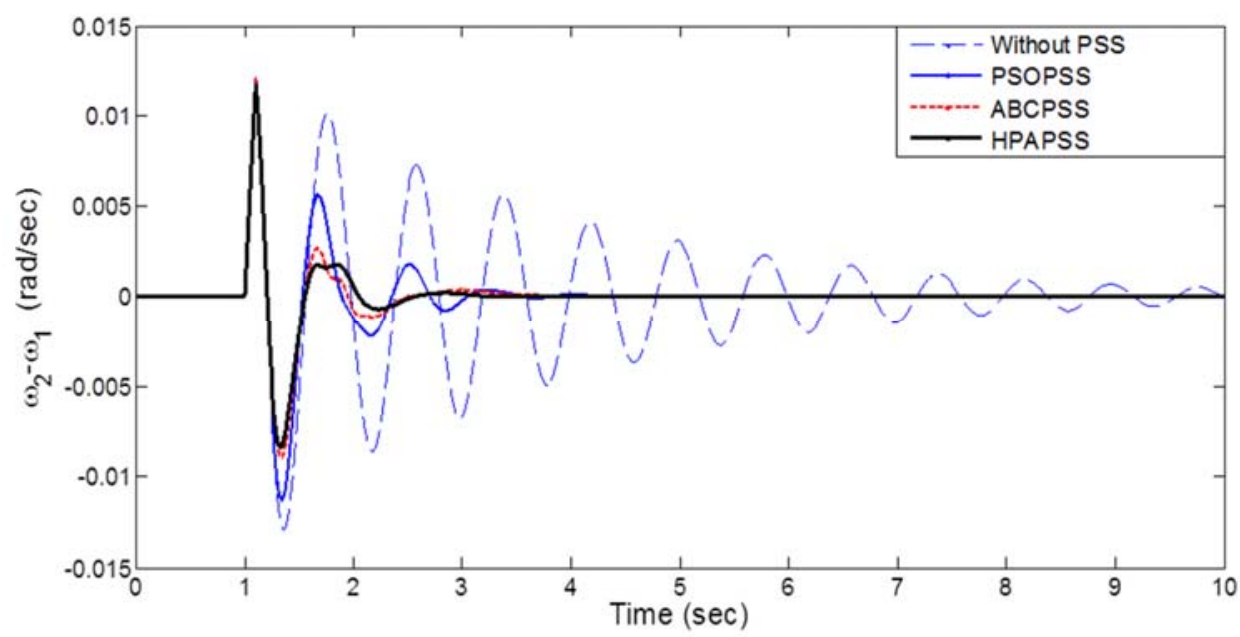

Şekil 10. Senaryo 1 için $\omega_{2}-\omega_{1}$ 'in cevab1 (Response of $\omega_{2}-\omega_{1}$ for scenario 1 ) 


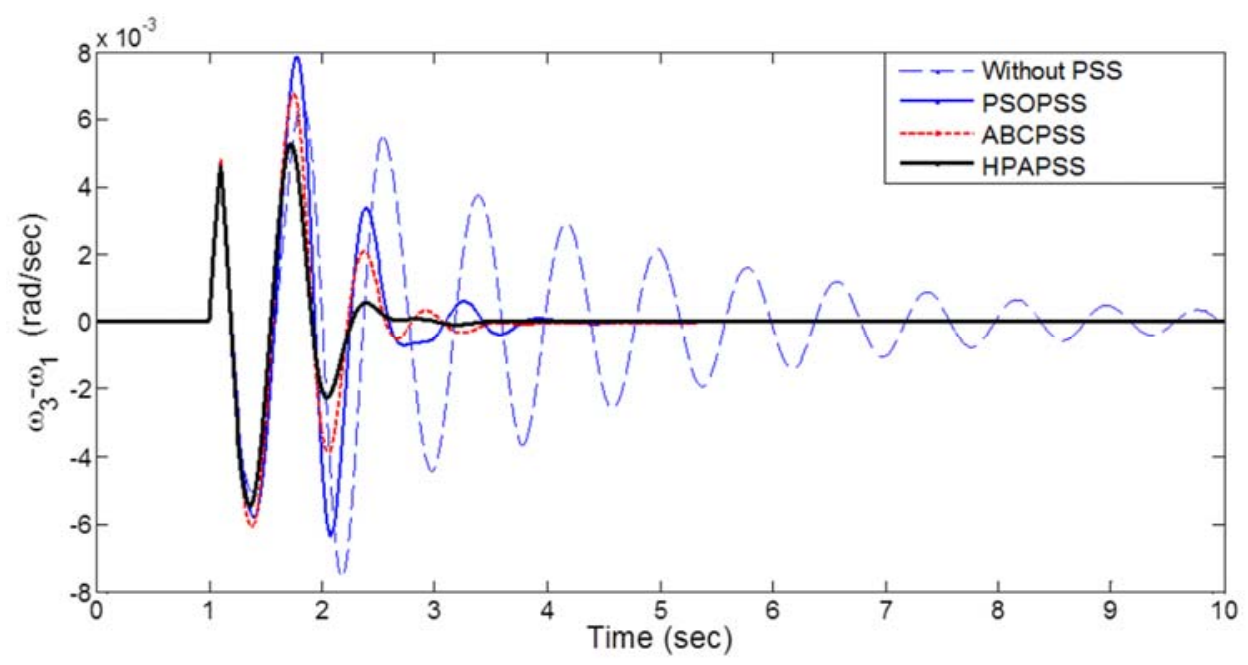

Şekil 11. Senaryo 1 için $\omega_{3}-\omega_{1}$ 'in cevab1 (Response of $\omega_{3}-\omega_{1}$ for scenario 1 )

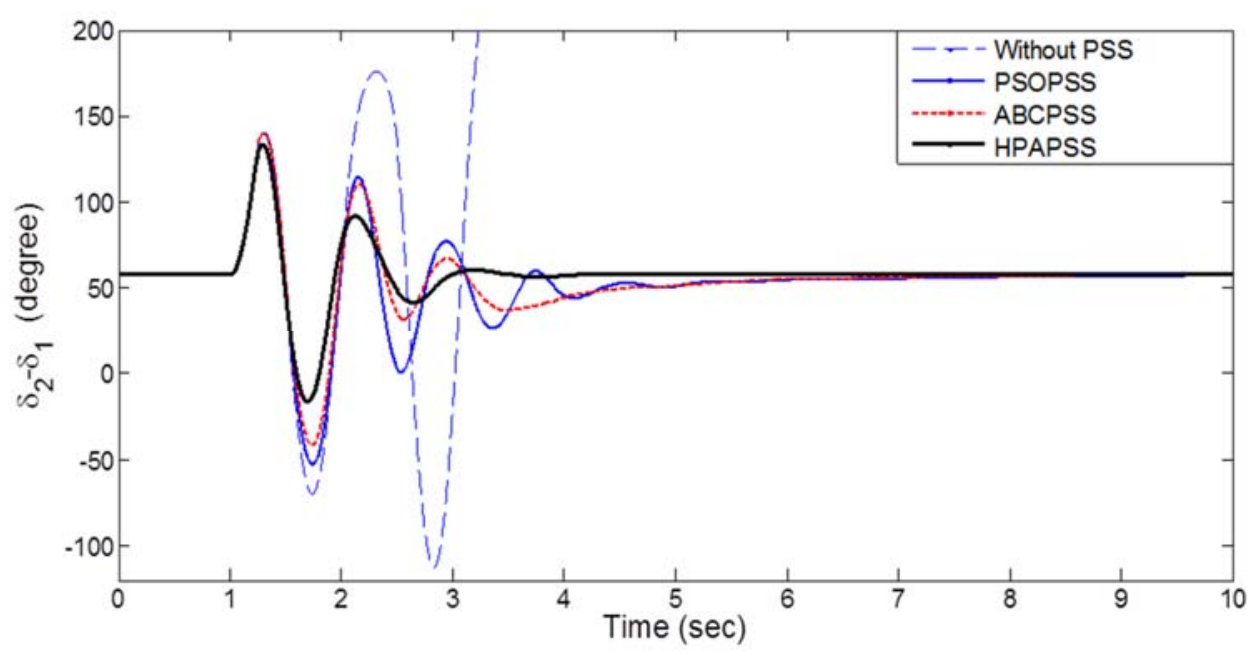

Şekil 12. Senaryo 2 için $\delta_{2}-\delta_{1}{ }^{\prime}$ in cevab1 (Response of $\delta_{2}-\delta_{1}$ for scenario 2 )

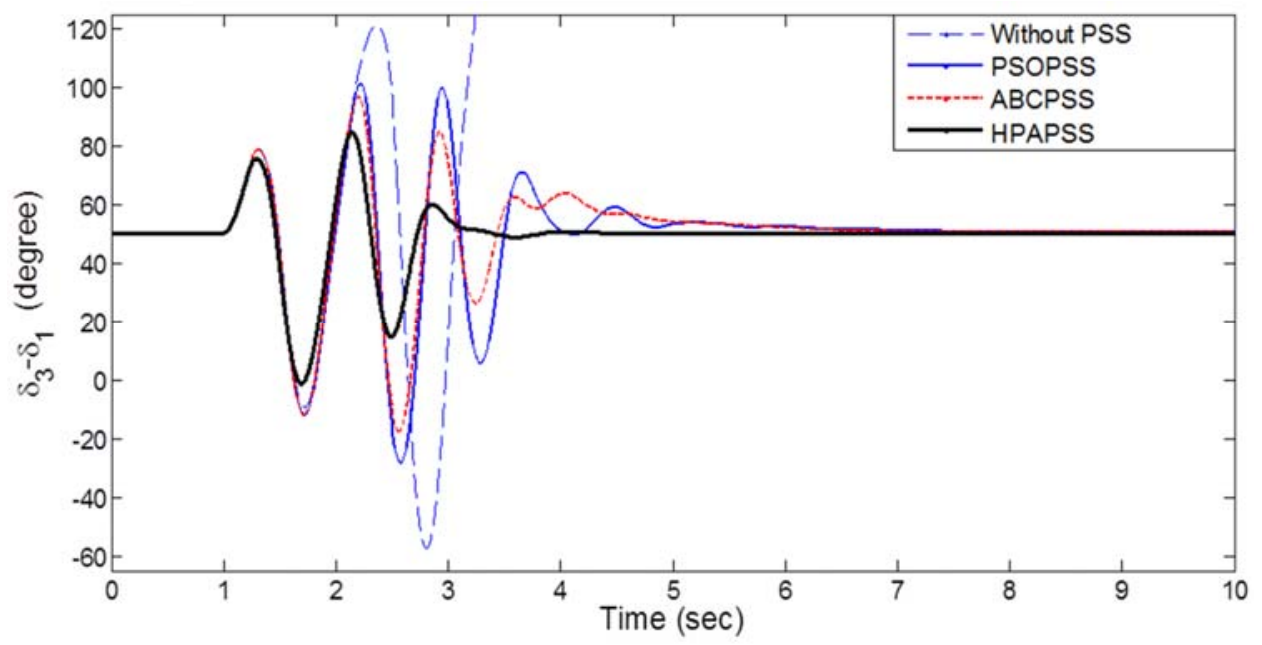

Şekil 13. Senaryo 2 için $\delta_{3}-\delta_{1}$ 'in cevab1 (Response of $\delta_{3}-\delta_{1}$ for scenario 2 ) 


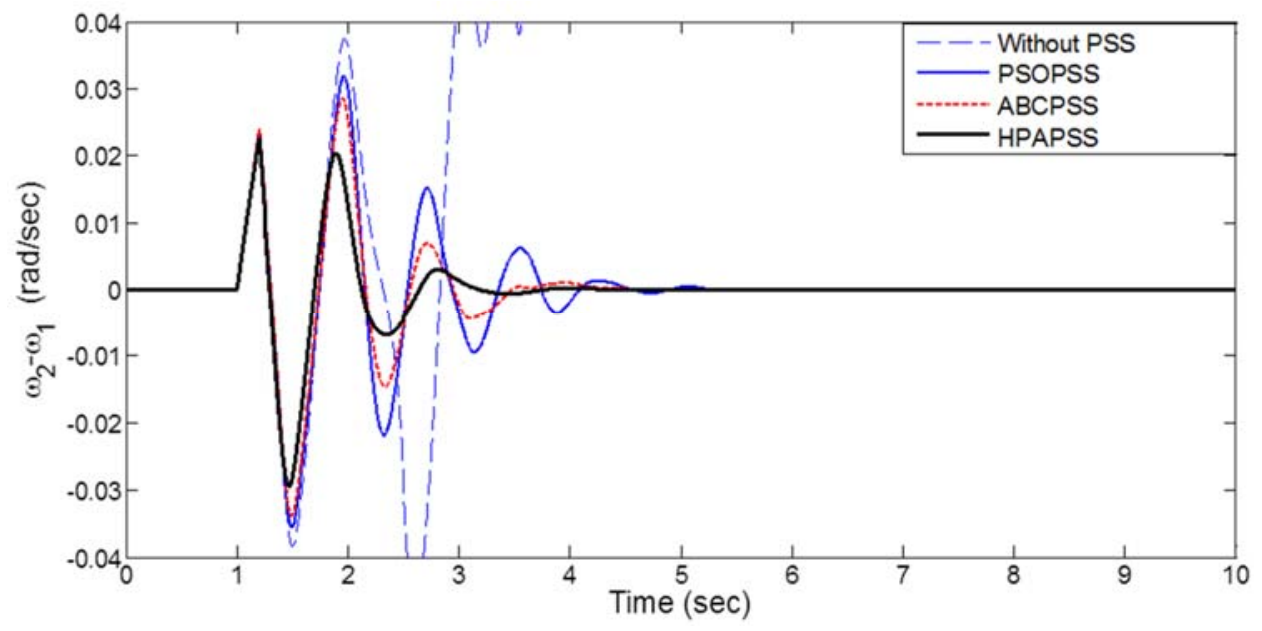

Şekil 14. Senaryo 2 için $\omega_{2}-\omega_{1}$ 'in cevab1 (Response of $\omega_{2}-\omega_{1}$ for scenario 2 )

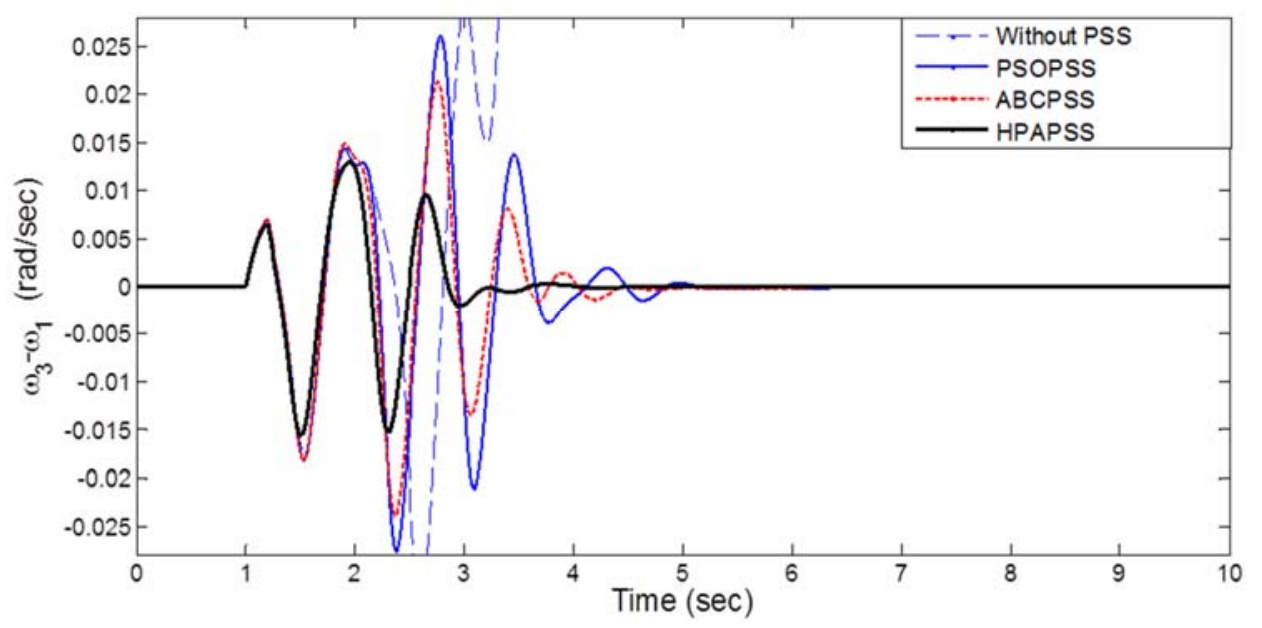

Şekil 15. Senaryo 2 için $\omega_{3}-\omega_{1}$ 'in cevab1 (Response of $\omega_{3}-\omega_{1}$ for scenario 2 )

Tablo 5. 5-7 hattı için kritik temizleme zamanı (Critical clearing time for line 5-7)

Arızalı hattın kritik temizleme zamanı (s)

\begin{tabular}{llll} 
Kontrolsüz & PSOPSS & ABCPSS & HPAPSS \\
\hline 0,167 & 0,218 & 0,224 & 0,232 \\
\hline
\end{tabular}

Tablodan apaçık görüleceği şekilde önerilen HPA destekli PSS'li sistemin kritik temizleme zamanı açısından geçici hal kararlılık performansı, PSOPSS ve ABCPSS'den daha yüksektir.

\subsubsection{Zaman cevabı performans indeksleri}

(Performance indices of time response)

Yerleşme zamanı ve maksimum aşımı yansıtan iki performans indeksi yardımıyla, parametreleri PSO, ABC ve HPA optimizasyon teknikleri ile en uygun hale getirilen PSS'li güç sistemlerinin (PSOPSS, ABCPSS ve HPAPSS) lineer olmayan zaman domenindeki performanslarının kıyaslanması yapıldı. Kullanılan bu iki indeks Eş. 22 ve Eş. 23 ile belirtilmiştir [1].

$$
\begin{aligned}
& P I_{1}=\sum_{i=2}^{m} \int_{0}^{t=t_{\text {sim }}}\left(\Delta \omega_{i-1}\right)^{2} d t \\
& P I_{2}=\sum_{i=2}^{m} \int_{0}^{t=t_{\text {sim }}}\left(t \Delta \omega_{i-1}\right)^{2} d t
\end{aligned}
$$

Burada $m$ generatör sayısını, $\mathbf{t}_{\text {sim }}$ simülasyon zamanını ve $\Delta \omega_{\mathrm{i}-1} i$. generatörün 1 . generatöre göre bağıl rotor hızını göstermektedir. Sistem zaman cevabının iyileştirilmesi için bu indekslerin değerlerinin küçük olması istenir. $t_{\text {sim }}=10 \mathrm{~s}$ alınmak suretiyle örnek güç sistemi modelinin zaman domeni simülasyonları yapılarak iki performans indeksinin değerleri hesaplanır. Senaryo 1 ve 2 durumları için bu indekslerin nümerik değerleri Şekil 16'da verilmiştir. Şekilden açıkça görüleceği gibi, parametreleri önerilen HPA ile optimize edilen sistemin (HPAPSS) indeks değerleri daha küçük görülmektedir. Önerilen PSS uygulanarak, elektromekanik salınım modlarındaki yerleşme zamanı ile maksimum aşım önemli derecede düşmektedir ve aynı zamanda tüm makinalardaki düşük frekanslı salınımlara iyi sönümleme sağlanmaktadır. 

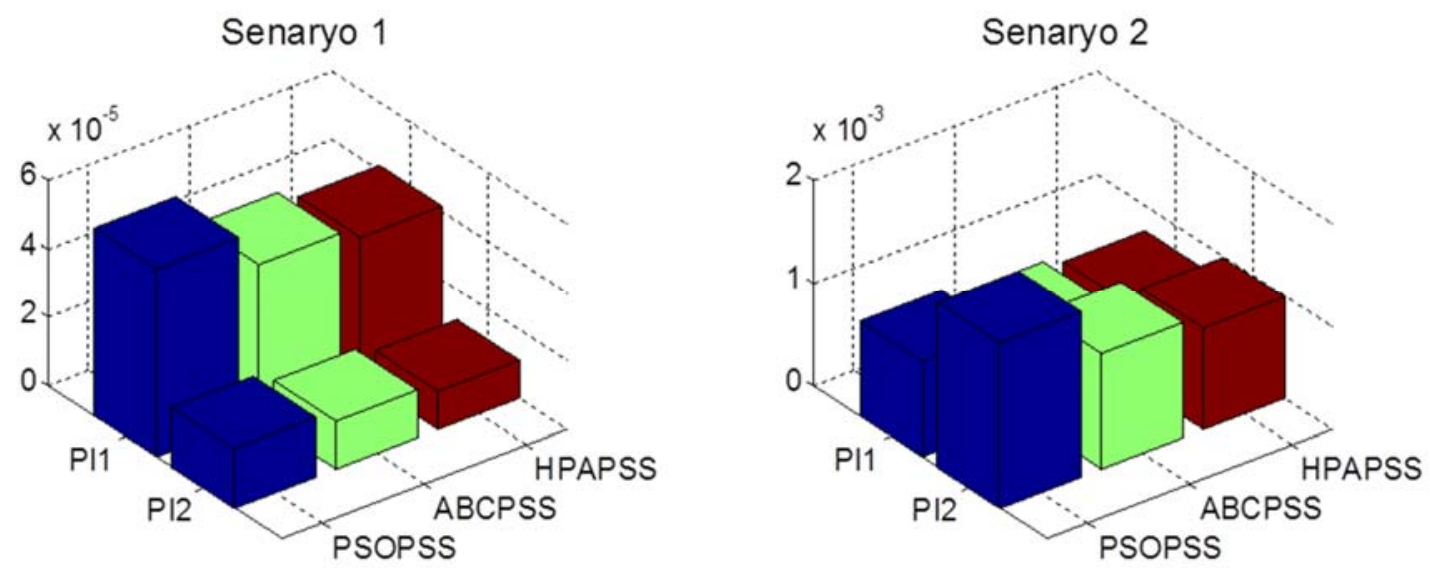

Şekil 16. Performans indekslerinin değerleri (Values of performance indices)

\section{SONUÇLAR (CONCLUSIONS)}

Bu çalışmada, sürü zekâsının basit anlaşılırlı̆̆ı, doğruya en yakın ve hızlı çözüm bulma özelliklerinden yararlanarak PSS kontrolör parametrelerinin önerilen tasarım yaklaşımıyla ayarlanmas1, yeni ve etkin bir hibrit optimizasyon tekniği olan HPA algoritması ile yapılmıştır. En uygun PSS parametrelerinin bulunması için kararlı k1lıcı tasarım problemi, yerleşme zamanı ve aşım miktarını minimize eden özdeğer tabanlı bir amaç fonksiyonu vasıtasıyla bir çeşit optimizasyon problemine dönüştürüldü ve PSO ile ABC algoritmalarının hibridizasyonu olan HPA ile çözüldü. Önerilen HPA destekli PSS (HPAPSS), büyük bozucu etkilere maruz kalan çok makinalı örnek güç sistemi üzerinde test edildi. Ek olarak, önerilen hibrit tabanlı tasarım yaklaşımının etkinliğini ve üstünlüğünü analiz etmek amaciyla, PSO ve ABC tabanlı PSS'ler ile ayrıntılı olarak karşılaştırıldı ve aşağıdaki sonuçlar elde edildi.

Yapılan özdeğer analizinde HPAPSS, sistemin elektromekanik modlarının sönüm karakteristiğini diğer iki algoritma tabanlı PSS'lere göre daha iyi düzeltmektedir.

Zaman domeni simülasyonlarından, farklı arıza durumları için hibrit algoritmanın düşük frekanslı salınımları hızlı söndürme yeteneğinin olduğu ve kritik arıza temizleme zamanını iyileştirdiği (arttırdığı) gözlenmiştir.

Diğer iki teknik (PSO ve ABC) ile karşılaştırıldığında, HPA algoritmasının yakınsama hızı, çözüm kalitesi ve hesaplama zamanı açısından üstün performansının olduğu gösterilmiştir.

PSOPSS ve ABCPSS'ye kıyasla bazı zaman cevabı performans indeks değerlerinden açıkça anlaşılacağı üzere; HPAPSS, sistemin yerleşme zamanını ve generatörlerdeki hız sapmalarını oldukça azaltmaktadır.

$\mathrm{Bu}$ çalışmadan elde edilen sonuçlardan, PSS sistem parametrelerini optimize etmek amaciyla literatürde bu konuya henüz uygulanmamış olan hibrit algoritmanın performansının PSO ve $\mathrm{ABC}$ algoritmalarından daha iyi olduğu görülmüştür.

\section{KAYNAKLAR (REFERENCES)}

1. Abido M.A., Abdel-Magid Y.L., Eigenvalue assignments in multimachine power systems using tabu search algorithm, Comput. Electr. Eng., 28 (6), 527-545, 2002.

2. Keumarsi V., Simab M., Shahgholian G., An integrated approach for optimal placement and tuning of power system stabilizer in multi-machine systems, Int. J. Electr. Power Energy Syst., 63, 132-139, 2014.

3. Ekinci S., Application and comparative performance analysis of PSO and ABC algorithms for optimal design of multi-machine power system stabilizers, Gazi Journal of Science, 29 (2), 323-334, 2016.

4. Khodabakhshian A., Hemmati R., Multi-machine power system stabilizer design by using cultural algorithms, Int. J. Electr. Power Energy Syst., 44 (1), 571-580, 2013.

5. Alkhatib H., Duveau J., Dynamic genetic algorithms for robust design of multimachine power system stabilizers, Int. J. Electr. Power Energy Syst., 45 (1), 242-251, 2013.

6. Ekinci S., Demiroren, A., Modeling, simulation and optimal design of power system stabilizers using ABC algorithm, Turk J Elec Eng \& Comp Sci, 24, 1532-1546, 2016.

7. Abido M.A., Parameter optimization of multimachine power system stabilizers using genetic local search, Int. J. Electr. Power Energy Syst., 23 (8), 785-794, 2001.

8. Abdel-Magid Y.L., Abido M.A., Al-Baiyat S., Mantawy A.H., Simultaneous stabilization of multimachine power systems via genetic algorithms, IEEE Trans. Power Syst., 14 (4), 1428-1439, 1999.

9. Hassan L.H., Moghavvemi M., Almurib H.A.F., Muttaqi K.M., Ganapathy V.G., Optimization of power system stabilizers using participation factor and genetic algorithm, Int. J. Electr. Power Energy Syst., 55, 668679, 2014.

10. Sundareswaran K., Razia Begum S., Genetic tuning of a power system stabilizer, Euro. Trans. Electr. Power, 14, 151-160, 2004.

11. Sun Z., Wang N., Srinivasan D., Bi Y., Optimal tunning of type-2 fuzzy logic power system stabilizer based on 
differential evolution algorithm, Int. J. Electr. Power Energy Syst., 62, 19-28, 2014.

12. Wang S.K, Coordinated parameter design of power system stabilizers and static synchronous compensator using gradual hybrid differential evaluation, Int. J. Electr. Power Energy Syst., 81, 165-174, 2016.

13. Ekinci S., Demiroren A., PSO based PSS Design for Transient Stability Enhancement, IU-Journal of Electrical \& Electronics Engineering, 15 (1), 18551862, 2015.

14. Labdelaoui H., Boudjema F., Boukhetala D., A multiobjective tuning approach of power system stabilizers using particle swarm optimization, Turk J Elec Eng \& Comp Sci, 24, 3898-3909, 2016.

15. Sambariya D.K., Prasad R., Robust tuning of power system stabilizer for small signal stability enhancement using metaheuristic bat algorithm, Int. J. Electr. Power Energy Syst., 61, 229-238, 2014.

16. Peres W., Oliveira E.J.D, Filho J.A.P., Silva Junior I.C.D., Coordinated tuning of power system stabilizers using bio-inspired algorithms, Int. J. Electr. Power Energy Syst., 64, 419-428, 2015.

17. Eke İ., Taplamacıoğlu M.C., Kocaarslan İ., Design of robust power system stabilizer based on Artificial Bee Colony Algorithm, Journal of the Faculty of Engineering and Architecture of Gazi University, 26 (3), 683-690, 2011.

18. Eslami M., Shareef H., Khajehzadeh M., Optimal design of damping controllers using a new hybrid artificial bee colony algorithm, , Int. J. Electr. Power Energy Syst., 52, 42-54, 2013.

19. Elazim S.M.A., Ali E.S., Optimal Power System Stabilizers design via Cuckoo Search algorithm, Int. J. Electr. Power Energy Syst., 75, 99-107, 2016.

20. Sheeba R., Jayaraju M., Sundareswaran K., Performance enhancement of power system stabilizer through colony of foraging ants, Electr. Power Compon. Syst., 42 (10), 1016-1028, 2014.

21. Ekinci S., Çok makinalı güç sisteminde açısal kararlılık analizi ve kontrolör parametre Optimizasyonu, Doktora Tezi, İstanbul Teknik Üniversitesi, Fen Bilimleri Enstitüsü, İstanbul, 2015.

22. Kıran M.S., Gündüz M., A recombination-based hybridization of particle swarm optimization and artificial bee colony algorithm for continuous optimization problems, Appl. Soft Comput., 13 (4), 2188-2203, 2013.

23. Sauer P.W., Pai M.A., Power system Dynamics and Stability, Prentice Hall, 1998.

24. Haltaş A., Alkan A., Karabulut M., Performance analysis of heuristic search algorithms in text classification, Journal of the Faculty of Engineering and Architecture of Gazi University, 30 (3), 417-427, 2015.

25. Kennedy J., Eberhart R.C., Swarm Intelligence, San Francisco, CA, USA: Morgan Kaufmann Publishers, 2001.

26. Fereidouni A.R., Vahidi B., Hoseini Mehr T., Tahmasbi M., Improvement of low frequency oscillation damping by allocation and design of power system stabilizers in the multi-machine power system, Int. J. Electr. Power Energy Syst., 52, 207-220, 2013.

27. Öztürk C., Hançer E., Karaboğa D., Automatic clustering with global best artificial bee colony algorithm, Journal of the Faculty of Engineering and Architecture of Gazi University, 29 (4), 677-687, 2014.

28. Karaboga D., Basturk B., On the performance of artificial bee colony (ABC) algorithm, Appl. Soft Comput., 8 (1), 687-697 2008.

29. Karaboga D., Özturk C., A novel clustering approach: Artificial Bee Colony (ABC) algorithm, Appl. Soft Comput., 11 (1), 652-657, 2011.

30. Akay B., Karaboga D., A modified Artificial Bee Colony algorithm for real-parameter optimization, Information Sciences, 192, 120-142, 2012.

31. Li G., Niu P., Xiao X., Development and investigation of efficient artificial bee colony algorithm for numerical function optimization, Appl. Soft Comput., 12 (1), 320332, 2012.

32. Adaryani M.R., Karami A., Artificial bee colony algorithm for solving multi-objective optimal power flow problem, Int. J. Electr. Power Energy Syst., 53, 219-230, 2013.

33. Kundur P., Power System Stability and Control. New York, USA: McGraw-Hill, 1994.

34. Anderson P.M., Fouad A.A., Power System Control and Stability, Ames, IA: Iowa State Univ. Press, 1977.

35. Ekinci S., Zeynelgil H.L., Demiroren A., A didactic procedure for transient stability simulation of a multimachine power system utilizing SIMULINK, Int. J. Electr. Eng. Educ., 53 (1), 54-71, 2016. 
